\title{
The snowline climate of the Alps 1961-2010
}

\author{
M. Hantel · C. Maurer · D. Mayer
}

Received: 14 October 2011 / Accepted: 30 April 2012 / Published online: 7 July 2012

(C) The Author(s) 2012. This article is published with open access at Springerlink.com

\begin{abstract}
We study the probability for snow cover at a climate station. Connecting stations with the same probability yields the corresponding snow line (a figure between zero and unity). The climatological snow lines in the Alps are implicit in the state function of snow duration. This function, specified by just five parameters, depends upon the mountain temperature, a linear combination of the mean temperature over Europe and the $3 \mathrm{D}$-coordinates of the stations. The influence of external parameters other than temperature (like snowfall, melting processes, station exposition) is treated as stochastic. The five state function parameters are gained for both winter (DJF) and summer (JJA) through a fitting algorithm from routine snow depth observations in 1961-2010 in Austria and Switzerland. Any desired snow line is defined by a linear surface with a characteristic value of the mountain temperature. The snow line appears when there is a cut between the surface and the orography. Temperature sensitivity of snow cover duration, analytically derived from the state function, is extreme at the median snow line (snow probability 0.50). Alpine-wide mean altitude of the median snow line is $793( \pm 36) \mathrm{m}$ in winter and $3.083( \pm 1.121) \mathrm{m}$ in summer. The snowline field slopes gently from west to east across the Alps (downward in winter, upward in summer) and oscillates up and down with the sea-
\end{abstract}

M. Hantel $(\bowtie) \cdot$ C. Maurer

Theoretical Meteorology Research Forum, Berggasse 11/2/3, 1090 Vienna, Austria

e-mail:michael.hantel@univie.ac.at

D. Mayer

Institute of Meteorology and Geophysics,

University of Vienna, Althanstrasse 14,

1090 Vienna, Austria sons. The sensitivity of the median snowline altitude to European temperature over the five decades of Alpine data is $166( \pm 5) \mathrm{m} /{ }^{\circ} \mathrm{C}$ in winter and $123( \pm 18) \mathrm{m} /{ }^{\circ} \mathrm{C}$ in summer. Global warming causes the snow lines to shift upward with time; in parallel, the area of the Alps that is at least $50 \%$ snow covered in winter shrinks by -7.0 $( \pm 4.1) \% / 10$ years.

\section{Introduction}

The snow limit concept represents the intuitive notion that there is a well-defined transition between snowcovered ground and ground free of snow. The position where this transition happens is often clearly visible in the field, particularly in the mountains, sometimes locally with an accuracy of less than a meter. Connecting these positions yields the snow limit. This concept has been applied from the daily time scale over monthly to annual and decade-long periods. For example, it has been used by Hann (1883) and various subsequent authors. Further, in the geographical literature, Louis (1955) has analyzed the notion of the snow limit in detail; Louis considered, with focus upon the budgets of glaciers, the climatological snow limit as the position at which total snowfall and total ablation are in balance. A worldwide map of the snow limit (in relation to the tree line) has been provided by Hermes (1955).

We have recently (Hantel and Maurer (2011)) studied the snow limit concept in the more general context of the snow line. The basis of the snow line is the relative seasonal snow duration, obtained from daily routine measurements of the snow depth at a climate station. We interpret this as the probability to encounter snow cover. Connecting stations with the 
same probability yields the corresponding snow line (a figure between zero and unity-see also the equivalent definition in the Dictionary of Earth Science, Parker (1997)). The snow limit is adopted for the specific value of $50 \%$; we refer to it as the median snow line. At the median snow line, the probability to encounter snow is equal to the probability to encounter no snow.

There is a physical reason for the significance of this boundary. The median snow line should be located where the sensitivity to temperature is extreme. In high and cold mountain regions with sizeable snow cover, the snow duration should be insensitive to an external large-scale warming or cooling; a similar reasoning applies to warm climate stations in the lowlands where there is no snow cover at all. Extreme temperature sensitivity should be found somewhere in between. This is in accord with general climatological experience (e.g., Laternser and Schneebeli (2003), Scherrer et al. (2004), and Durand et al. (2009)).

With this qualitative background, Hantel and Maurer (2011) have developed the quantitative state function of snow duration for the coherent mountain region of the Alps, for the climate period 1961-2000. The corresponding theory yields a formula for the state function which implies the definition of the snow lines and implies further that the snowline field is controlled by the mountain temperature, a linear combination of European temperature and 3D-station coordinates.

In this study, we want to corroborate these results, with the following innovative components. First, we will present evaluations for the 50-year climate epoch in 1961-2010, both for winter (DJF) and summer (JJA), for the Alpine region consisting of Austria (A) and Switzerland $(\mathrm{CH})$; the results will be quite well in accord with our previous evaluations. Further, we will describe and implement a modified fitting algorithm to derive the parameter estimates for the state function; this theoretically improved method does not much change the results but in addition yields statistically sound estimates of the explained variance (Appendix 1). Finally, we will extend the mean snowline surfaces, valid for the entire Alpine region, into a couple of selected individual valleys; this may demonstrate the applicability, including its limits, of the present approach to the climate of a local station.

The paper is organized as follows: In the next section, we give a skeleton review of the model, stratified into its different levels of application. Data management is covered in Section 3. In accord with our basic hypothesis (i.e., the dependence of the snowline field solely upon the mountain temperature), we use as observed temperature data only the mean seasonal temperature, averaged over Europe, and as observed snow data only the daily snow depth at the climate stations (plus, of course, the 3D-station coordinates); other possible input parameters (e.g., local station temperature, snowfall, quantities describing the melting process, or the exposition of a climate station to radiation) are not used. In Section 4, we present standard ("naive") statistics without reference to the model. The model results come in Section 5 for the entire Alpine region and in Section 6 for the selected Alpine valleys. Trend estimates are discussed in Section 7. An outlook is given in Section 8.

\section{Review of the model}

The snowline model as we want to use it here (Hantel and Maurer (2011)) is based upon a snow cover model, originally designed for Austrian data by Hantel (1992), further developed in paper I (Hantel et al. (2000)), extended to Swiss data in paper II (Wielke et al. (2004) along with Wielke et al. (2005)) and applied to all-Alps data in paper III (Hantel and Hirtl-Wielke (2007)). The unifying concept is the hypothesis that the seasonal snow cover at a climate station is primarily controlled by the seasonal surface air temperature of the station. The station temperature, however, can eventually be replaced by the montain temperature, a linear combination of the area mean surface temperature $T$ over Europe and the 3D-station coordinates. In this section, we review three different applications of the model, schematically sketched in Fig. 1.

\subsection{Laboratory model (see Fig. 3 of Hantel and Hirtl-Wielke (2007))}

In the physical laboratory (first column of Fig. 1) with actual temperature $\vartheta$, we observe two phases $v$ of pure water: liquid water $(v=0)$ for $\vartheta$ above $t_{0}=0{ }^{\circ} \mathrm{C}$ and ice $(v=1)$ for $\vartheta$ below $t_{0}$. The probability $P$ to encounter ice is equal to the ensemble average $\langle v\rangle$. We further assume that there are stochastic temperature fluctuations, normally distributed, with ensemble mean $\langle\vartheta\rangle$ and standard deviation $\epsilon$. For this setting, $P$ is controlled by the temperature parameters as follows:

$P(\langle\vartheta\rangle, \epsilon)=\Phi(\chi) \quad$ with $\quad \chi=\left(t_{0}-\langle\vartheta\rangle\right) / \epsilon$.

$\Phi$ is the Gaussian error function defined as (Bronstein et al. (1999)):

$\Phi(\chi)=\frac{1}{\sqrt{2 \pi}} \int_{\vartheta=-\infty}^{\chi} e^{-\vartheta^{2} / 2} \mathrm{~d} \vartheta$. 


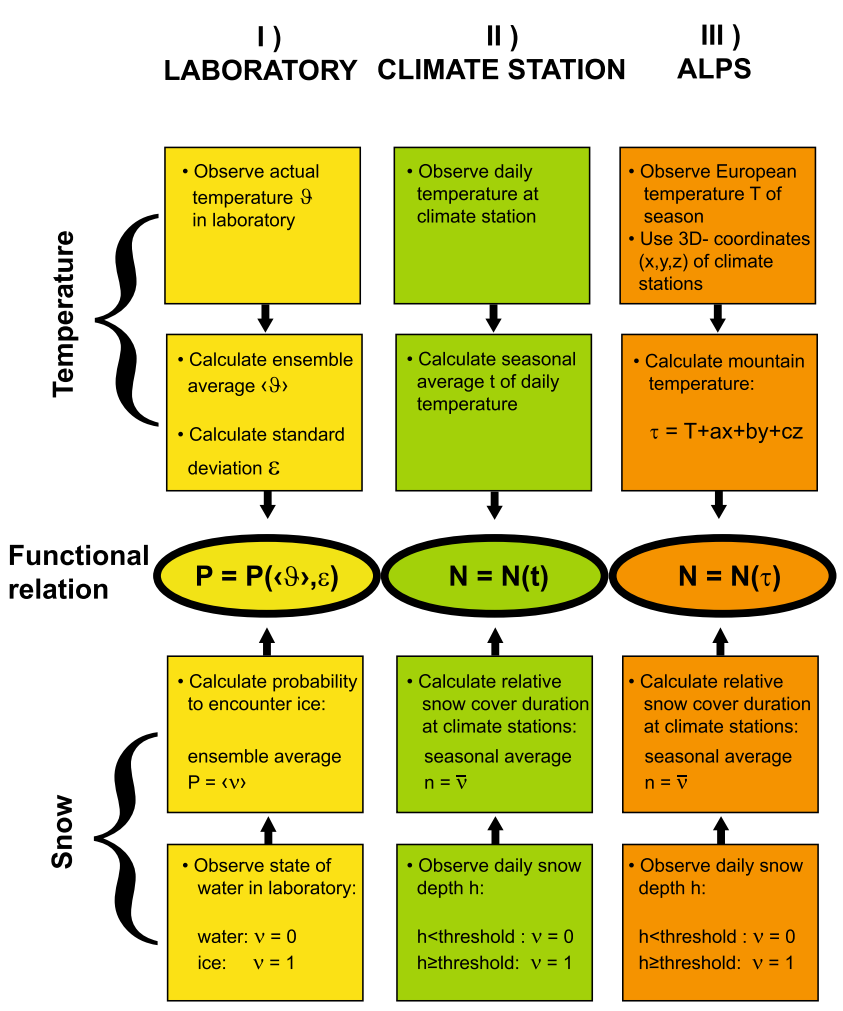

Fig. 1 Poster of different model versions. The unifying theoretical concept is a Gaussian error function $\Phi(\chi)$. It serves as an exact description of ice probability $P$ with $\chi(\langle\vartheta\rangle, \varepsilon)$ in the laboratory (first column) and as logistic function $N$ with $\chi(t)$ to describe snow probability as a function of local temperature $t$ at individual climate stations (second column). With the mountain temperature $\tau$ and with $\chi(\tau)$, the error function serves as state function $N$ to describe a relative seasonal snow duration, gained from snow data (plus European temperature and 3D-station coordinates), without using $t$ (third column)

This model (Hantel and Hirtl-Wielke (2007)) yields the probability to observe ice in the laboratory.

\subsection{Climate station model (see Fig. 4 of Hantel et al. (2000))}

Application of the model Eq. 1 to station data is straightforward (second column of Fig. 1). We replace the standard deviation $\epsilon$ by the negative parameter $s_{0}=$ $-(\epsilon \sqrt{2 \pi})^{-1}$ and put

$N(t)=\Phi(\chi) \quad$ with $\quad \chi=\sqrt{2 \pi} s_{0}\left(t-t_{0}\right)$.

$N$ is the snow duration function. Its parameters $s_{0}$ and $t_{0}$ are fitted to seasonal snow cover $n$ and mean temperature $t$, observed at a given climate station.

The parameters $s_{0}$ and $t_{0}$ should principally not differ from climate station to climate station. In other words, data from different stations at different elevations can be lumped together into $N$. This has, e.g., been done in
Fig. 1 of Hantel and Hirtl-Wielke (2007) for Austrian stations and in Fig. 5 of Hantel and Maurer (2011) for all-Alps stations, both for the winters (DJF) of 19612000.

This type of plot reveals the dependence of the snow duration upon station temperature. However, the altitude dependence of temperature at the climate stations is mixed with the large-scale climate temperature of Europe. It follows that snowline information cannot be gained from $N(t)$.

\subsection{Alpine-wide model (see, e.g., Fig. 6 of Hantel and Maurer (2011))}

In order to identify snow lines, we note that the station temperature $t$ is influenced by the large-scale climate process, represented by the European temperature $T$ and by local effects, represented by the position $(x, y, z)$ of the climate station. This suggests to introduce the mountain temperature:

$\tau=T+a x+b y+c z$.

The model in Eq. 4 can be used for a multilinear regression analysis of $t$. The parameters $a, b$, and $c$ would be the constants of this expansion. They would be gained through fitting the observed $t$ against the predictor function $\tau$.

In our application of the model (third column of Fig. 1), we go a step beyond: We will get the expansion parameters $a, b$, and $c$ not from the observed $t$ but from the observed $n$, by replacing $t$ through $\tau$ in Eq. $3 ; t_{0}$ is replaced by the reference constant $\tau_{0}$. This yields, with $\Phi$ as in Eq. 2, the state function of snow duration:

$N(\tau)=\Phi(\chi) \quad$ with $\quad \chi=\sqrt{2 \pi} s_{0}\left(\tau-\tau_{0}\right)$.

$N(\tau)$ is specified through the parameter vector $\left(s_{0}, \tau_{0}, a, b, c\right)$. Time $\theta$ is implicit in the data vector $(n, T, x, y, z)$ through the time dependence of the largescale European temperature $T(\theta)$. The parameter vector is estimated from the data vector trough a pertinent fitting routine (see Section 3.8).

With the strategy summarized in Fig. 1, we will fulfill the following goals:

- Split the station temperature $t$, through the concept Eq. 4 of mountain temperature $\tau$, into a European scale and a local scale component;

- Show that $\tau$ (which now replaces $t$ ) can be gained from the snow duration data; 
- Represent the snow cover of the entire Alps with one nonlinear profile, the state function $N(\tau)$ of snow duration;

- Show that $N$ is controlled by European temperature $T$;

- Specify the median snow line by choosing $\tau=\tau_{0}$ in Eq. 4; the corresponding linear function of $x, y, z$ for fixed $T$ generates the median snow line (see Figs. 12 and 13 below).

The progress achieved is that all relevant properties of the snow cover, including the snowline field, across the 50-year observation period, can be analytically derived from the state function $N(\tau)$. We begin with the slope profile of the state curve:

$\frac{\partial N}{\partial T}=\frac{\mathrm{d} N}{\mathrm{~d} \tau}=\frac{\mathrm{d} \Phi}{\mathrm{d} \chi} \cdot \frac{\mathrm{d} \chi}{\mathrm{d} \tau}=s_{0} \exp \left(-\chi^{2} / 2\right)$

$$
\left[\frac{\mathrm{d} N}{\mathrm{~d} \tau}\right]_{\tau=\tau_{0}}=s_{0} .
$$

$\chi$ is specified through Eq. 5. As noted in Hantel et al. (2000), the partial derivative of $N$ with respect to $T$ (understood for fixed station vector $x, y, z$ ) is equal to the slope with respect to $\tau$. We interpret these derivatives as sensitivities. Thus, the first equation of Eq. 6 represents the entire sensitivity of Alpine climatological snow cover with respect to the European temperature. The sensitivity is maximum for $\tau=\tau_{0}$, adopted at the altitude of the median snow line; above and below the sensitivity decreases and becomes zero at very low and very high altitudes. The half width of the sensitivity profile, transformed from the argument $\tau$ to the altitude argument $z$, is

$D=\underbrace{2\left(\frac{\log 2}{\pi}\right)^{0.5}}_{\approx .94} \frac{1}{s_{0} c}$.

$D$ does not depend on $\tau$ and thus is independent also upon $T$. By solving Eq. 4 for $z=H$, we find the altitude of an arbitrary snow line $n$ :

$H(n, T, x, y)=\frac{\tau(n)-T-a x-b y}{c}$.

$\tau(n)$ in this formula follows from Eq. 5 as the inverse $N^{-1}(n)$ of the state function. The function $H$, for fixed $T$, is a linear surface which, by cutting across the orography of the Alps, generates the pertinent snow line (Figs. 12 and 13). Temperature sensitivity of the snowline altitude, along with the slope components of the surface in eastward and northward direction, is given through

$\frac{\partial H}{\partial T}=-\frac{1}{c} ; \quad \frac{\partial H}{\partial x}=-\frac{a}{c} ; \quad \frac{\partial H}{\partial y}=-\frac{b}{c}$.

These formulae will be used below. Further derivatives with respect to altitude $z$ (i.e., vertical gradient) and with respect to time $\theta$ (i.e., trend) can be found from the formulae in Eqs. 4, 5, and 6:

$$
\begin{aligned}
& \frac{\partial N}{\partial z}=\frac{\mathrm{d} N}{\mathrm{~d} \tau} \frac{\partial \tau}{\partial z}=\left(s_{0} e^{-\chi^{2} / 2}\right) \cdot c \\
& \frac{\partial N}{\partial \theta}=\frac{\mathrm{d} N}{\mathrm{~d} \tau} \underbrace{\frac{\partial \tau}{\partial T}}_{=1} \frac{\mathrm{d} T}{\mathrm{~d} \theta}=\left(s_{0} e^{-\chi^{2} / 2}\right) \cdot \frac{\mathrm{d} T}{\mathrm{~d} \theta} .
\end{aligned}
$$

This implies that both gradient and trend of $N$ are extreme at the median snow line (i.e., at $\chi=0$ ); above and below both decrease to zero with half-width $D$. Finally, the trend of the altitude of a given snow line follows from Eq. 8:

$\frac{\partial H}{\partial \theta}=\frac{\partial H}{\partial T} \frac{\mathrm{d} T}{\mathrm{~d} \theta}=-\frac{1}{c} \cdot \frac{\mathrm{d} T}{\mathrm{~d} \theta}$.

This implies that the altitudes of all snow lines have the same trend. In order to use Eqs. 10 and 11 for trend estimates, it is not sufficient to apply the present model. Also, required is an external estimate of the European temperature trend $\mathrm{d} T / \mathrm{d} \theta$ (e.g., from climatological data of the past or from a climatological model forecast).

\section{Data management}

The data vector $(n, T, x, y, z)$ is organized around the independent arguments $x, y$, and $z$ (which are the 3Dcoordinates of the climate station) and time $\theta$. Resolutions of $\theta$ used in this study are 1 day $\left(\theta^{* *}\right), 1$ month $\left(\theta^{*}\right)$, and one season $(\theta$ without superscript, winter $=$ DJF and summer $=\mathrm{JJA}),{ }^{1}$ different for temperature and for snow.

\footnotetext{
${ }^{1}$ The first winter in 1961 comprises only snow and temperature data of the months January and February, while the last winter in 2010 comprises data of December 2009 and January and February 2010.
} 
Table 1 Parameters of snow duration state function, period 1961-2000, DJF, $5 \mathrm{~cm}$

\begin{tabular}{llrrr}
\hline & \multicolumn{1}{c}{ All Alps } & \multicolumn{1}{c}{$\mathrm{A}+\mathrm{CH}^{\mathrm{b}}$} & \multicolumn{1}{c}{$\mathrm{A}+\mathrm{CH}^{\mathrm{c}}$} & $-0.17( \pm 0.01)$ \\
\hline$s_{0}\left({ }^{\circ} \mathrm{C}^{-1}\right)$ & $-0.17( \pm 0.01)$ & $-0.16( \pm 0.01)$ & $-5.91( \pm 0.57)$ & $-0.19( \pm 0.01)$ \\
$\tau_{0}\left({ }^{\circ} \mathrm{C}\right)$ & $-5.01( \pm 0.69)$ & $-6.50( \pm 0.68)$ & $-0.36( \pm 0.06)$ & $-5.43( \pm 0.55)$ \\
$a\left({ }^{\circ} \mathrm{C} /{ }^{\circ} \mathrm{lon}\right)$ & $-0.45( \pm 0.06)$ & $-0.38( \pm 0.06)$ & $0.33( \pm 0.25)$ & $-0.34( \pm 0.05)$ \\
$b\left({ }^{\circ} \mathrm{C} /{ }^{\circ} \mathrm{lat}\right)$ & $0.42( \pm 0.24)$ & $0.29( \pm 0.26)$ & $-9.57( \pm 0.91)$ & $0.49( \pm 0.22)$ \\
$c\left({ }^{\circ} \mathrm{C} / \mathrm{km}\right)$ & $-8.10( \pm 1.12)$ & $-10.52( \pm 1.12)$ & $-9.02( \pm 1.03)$ \\
\hline
\end{tabular}

Compare columns 1 and 3 for the impact of the different databases (all Alps versus $\mathrm{A}+\mathrm{CH}$ ). Compare columns 2, 3, and 4 for the impact of the different data quality criteria (i.e., "saturation" and "correlation"- these are discussed in Section 3.4 and 3.6). Evaluations in this table are made with the nonlinear fit (see Appendix 1).

${ }^{a}$ From Hantel and Maurer (2011), $r<0.0$ (see Fig. 6)

${ }^{\mathrm{b}}$ This study, all unsaturated station seasons

${ }^{\mathrm{c}}$ This study, $r<0.0$

${ }^{\mathrm{d}}$ This study, $r<-0.3$

\subsection{Representativeness of Austria + Switzerland for the Alps}

In this study, we will use only snow cover data from Austrian and Swiss routine climate stations. This data basis corresponds to a combination of the data volume used in papers I and II. Main reason was the decision to cover the 50-year period 1961-2010. Extension of the database 1961-2000 for Austria (used in papers I and III) and Switzerland (used in papers II and III) by 10 years was easy to achieve. On the other hand, the extension of the database for Germany, France, Slovenia, and Italy would have been more involved and we skipped it for the present study.

This is justified since the results of the 40-year period considered in Hantel and Maurer (2011) do not significantly differ if we either use the all-Alps data or only data from $\mathrm{A}+\mathrm{CH}$. Both show essentially the same result within data accuracy as seen in columns 1 and 3 of Table 1 . Thus, by restricting the present evaluation to the climate stations from Austria and Switzerland, we will yet be able to obtain results representative for the entire Alps.

\subsection{European temperature}

We adopt, in the same manner as in Hantel and Maurer (2011), the monthly gridded Climate Research Unit (CRU) temperatures (Brohan et al. (2006)) with a horizontal resolution of $0.5^{\circ}$ as a temperature database. These we linearly average in horizontal direction over the Alpine-dominated part of central Europe (5.5 $17.5^{\circ} \mathrm{E}$ and $43.5^{\circ}-49.5^{\circ} \mathrm{N}$, identical to the rectangle sketched in Figs. 4 and 5) and with respect to time over winter (DJF) and summer (JJA). This procedure yields a time series (not reproduced here) of 50 values of European temperature $T(\theta)$ characterizing each winter and summer of the observation period 1961-2010 with one temperature per season and per year (time parameter $\theta) .^{2}$

\subsection{Snow duration and threshold}

Original observation is snow depth $h$, measured daily (time parameter $\theta^{* *}$ ) at each climate station (coordinates of available stations $\left.x^{* *}, y^{* *}, z^{* *}\right)$. From $h$, a daily value $v=1$ or $v=0$, depending upon threshold, is derived. The seasonal average of $v$ is the snow duration: $n=\bar{v}$. Thus, $n=n\left(\theta, x^{* *}, y^{* *}, z^{* *}\right)$ with yearly resolution (one value per season and station).

The impact of the threshold for discriminating $h$ has been investigated by several authors. For example, Haiden and Hantel (1992) used a 1-cm data set, while Fliri (1992) recommends a minimum of $2 \mathrm{~cm}$. Beniston (1997) has considered snow depth thresholds from 1 up to $150 \mathrm{~cm}$.

Here, we choose $5 \mathrm{~cm}$ for winter, following paper I and Hantel and Maurer (2011), and $2 \mathrm{~cm}$ for summer, following Fliri (1992) and Gottfried et al. (2011); the latter authors have demonstrated (Table S5 in supplementary data of their paper) that in summer, the impact of the threshold upon the results is minor for thresholds from 1 to $4 \mathrm{~cm}$.

\subsection{Saturation of snow data}

Snow duration data $n=0$ and $n=1$ are called saturated. They do not carry relevant information which

\footnotetext{
${ }^{2}$ The time series of the CRU temperature presently available ends in 2009. In order to prolong the series by 1 year, we use the fact that the mean temperature of the $\mathrm{A}+\mathrm{CH}$ stations is highly correlated $(98 \%)$ with the CRU temperature. Thus we determined the 49-year average $\bar{t}_{\mathrm{A}+\mathrm{CH}}$ and the 49-year average $\bar{T}_{\mathrm{CRU}}$. The missing CRU temperature for 2010 is generated as follows: $T_{\mathrm{CRU}}{ }^{(2010)}={ }^{t} \mathrm{~A}+\mathrm{CH}^{(2010)}+\left(\bar{T}_{\mathrm{CRU}}-\bar{t}_{\mathrm{A}+\mathrm{CH}}\right)$. The correction is $1.8^{\circ} \mathrm{C}$.
} 
Table 2 Overview of data selection

\begin{tabular}{llrcrr}
\hline & & Total & Unsaturated & Weak & Strong \\
\hline DJF & Stations & 145 & 142 & 128 & 91 \\
& Seasons & 7,250 & 4,509 & 4,379 & 3,463 \\
\multirow{2}{*}{ JJA } & Stations & 145 & 58 & 27 & 15 \\
& Seasons & 7,250 & 768 & 646 & 447 \\
DJF $^{a}$ & Stations & 84 & 76 & 63 & 50 \\
\hline
\end{tabular}

${ }^{\mathrm{a}}$ From (Hantel et al. 2000)

makes them unacceptable as measurements. This point has been extensively discussed in paper I and again by Gottfried et al. (2011) and Hantel and Maurer (2011). The reason is that the daily snow "observation" parameter $v$ is Bernoulli distributed and as such has a parabolic variance distribution with variance zero for both $\bar{v}=0$ and $\bar{v}=1$. It follows that saturated observations have infinite accuracy which would make their contribution infinite in the cost function of the subsequent data fit.

Saturated data are dropped at the beginning of the evaluation procedure. The original data minus the saturated data will be referred to as the processed data. Saturation is by far the most important reason for excluding station seasons or even the complete data of one station (compare Table 2 and Appendix 2). Each of the remaining stations contains at least one unsaturated $n$ value (most of them contain many more).

\subsection{Altitude distribution of available $n$ data}

Figure 2 gives the number of processed snow duration observations (i.e., number of station seasons) available

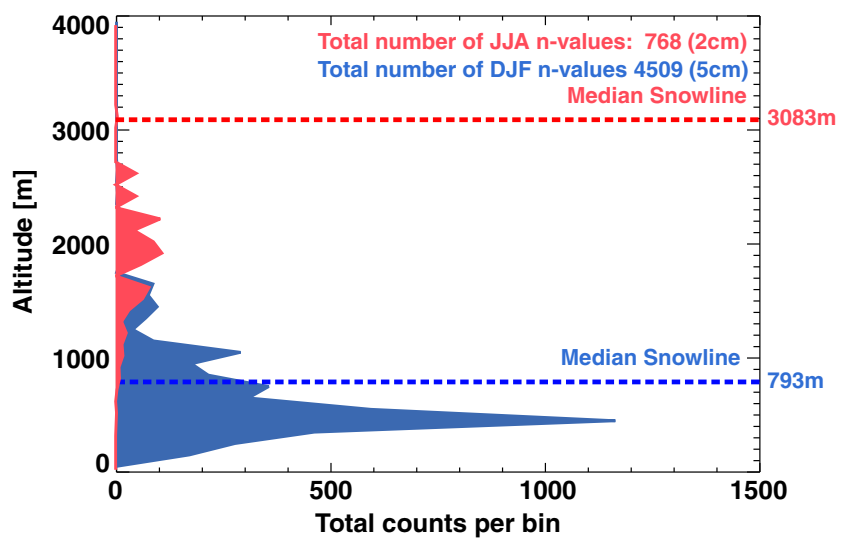

Fig. 2 Vertical frequency distribution of processed snow duration data from Austrian and Swiss climate stations (bin size $=$ $100 \mathrm{~m}$ ). For both seasons (winter in blue, threshold $5 \mathrm{~cm}$; summer in red, threshold $2 \mathrm{~cm}$ ), the altitude of median snow line is drawn as dashed line for Austria plus Switzerland as a function of altitude. The figure shows that in winter, the altitude of the median snow line is approximately located in the center of the station data whereas in summer it is located higher than most of the observed data. Thus, the winter state function will be superior in accuracy to the summer state function.

\subsection{Correlation criteria for climate stations}

In order to enhance data quality, we have calculated the linear correlation coefficient $r$ between $T$ and $n$ and have investigated the impact of excluding stations with $r>0$ ("weak correlation condition") and with $r>-0.3$ ("strong correlation condition"). We used the strong condition in paper I for the Austrian data set and in paper II for the Swiss data set. In our recent evaluations with the all-Alps data set, we used the weak condition, both for winter (Hantel and Maurer (2011)) and summer (Gottfried et al. (2011)).

In the present study, $r$ was determined for both seasons and is reproduced for winter in Fig. 3 versus altitude. The stations that violate the two correlation conditions (red and blue rhomboids) tend to be concentrated at greater altitudes; these are mainly located in the inner Alpine valleys (see particularly Fig. 4). Further, the correlation of most of the red stations is based on only a few station seasons (see Appendix 2).

The impact of the two correlation criteria upon the number of stations used is summarized in Table 2 . We introduced the criteria in paper I mainly for the purpose to improve the data quality. Starting from 76 unsaturated stations in Austria for winter, our weak

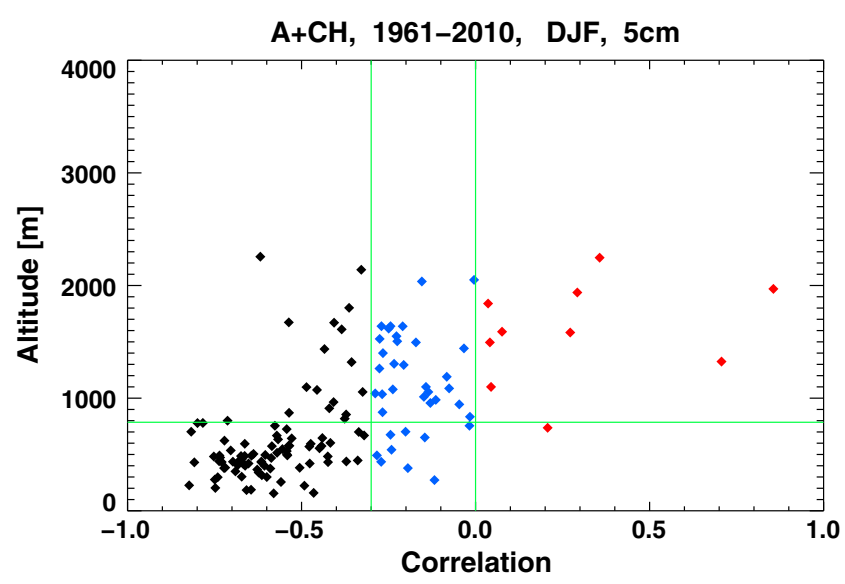

Fig. 3 Linear correlation coefficient $r(T, n)$ plotted versus altitude. Positive $r$ in red, negative $r$ larger than -0.3 in blue, $r$ less than -0.3 in black 


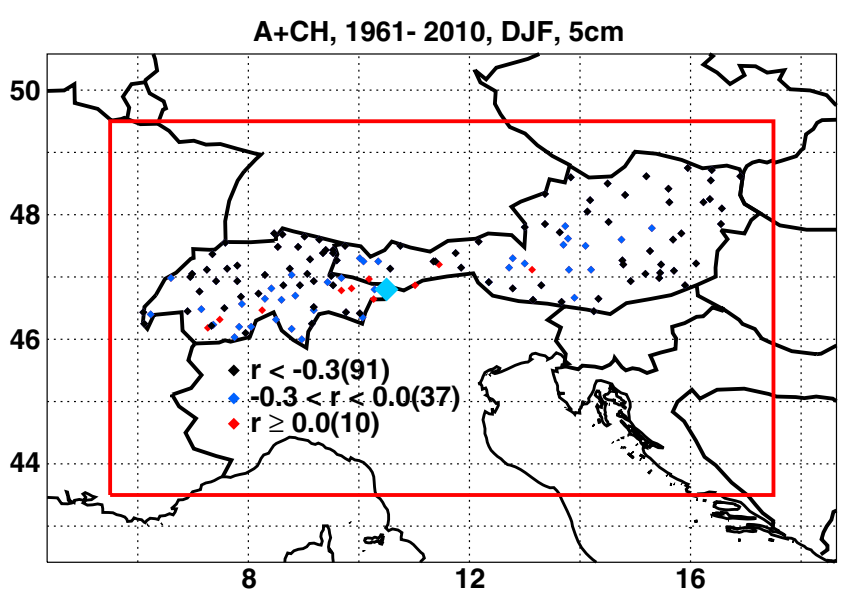

Fig. 4 Location of Austrian and Swiss climate stations, season winter (DJF). Red (blue) rhomboids: Stations that are excluded because they do not pass the weak (strong) correlation criterion (see also Fig. 3). Black rhomboids: Stations selected for the eventual data fit. Thick blue rhomboid: Reference zero for coordinate vector $(x, y, z)$ in the definition of mountain temperature

criterion excluded $17 \%$ of the stations; the strong criterion in paper I excluded another $17 \%$. Both measures together reduced the number of stations by $34 \%$ down to 50 eventually used for the evaluation (last line of Table 2).

The present data reduction for winter (first line of Table 2) starts from 142 processed stations leading to 128 stations which obey the weak criterion and to 91 stations which obey the strong criterion; this corresponds to a net reduction by $36 \%$ of the processed stations. For the purposes of the present study, we adopt the strong correlation criterion, essentially for the same reasons that have been considered relevant in paper I. Justification for our approach was that it excluded a priori erroneous and/or misleading data and enhanced the negative slope dependence of $n$ upon $T$ in the data set. A significant positive slope dependence (i.e., increase in $n$ accompanied by increase in $T$ ) appeared only possible if the snow duration is governed by the amount of snowfall and not by the temperature after the snowfall, as assumed throughout our model (which includes the present model suite); this would imply that the snowfall amount is higher for high temperatures (e.g., due to the additional effect of moisture). It now appears that it is indeed the snowfall mechanism which causes some of the positive and most of the slightly negative correlation stations seen in Fig. 3.

In accord with papers I and II, stations that violate the strong correlation criterion (red and blue dots in Fig. 3) will be excluded in the present evaluation. As Table 2 shows, 3,463 station seasons (out of 4,509, corresponding to $77 \%$ ) survive our strong correlation criterion in winter (58 \% in summer); thus, our remaining database is still more than sufficient. Geographic arrangement of the stations is shown in Figs. 4 and 5. These arguments in favor of our strict data quality requirements may not appear urgent because including the stations that violate the correlation conditions does not conspicuously change the eventual parameters of the fit that yields the snowline surface as given by Eq. 8. This is seen in Table 1 above (second to fourth columns): The parameters of the state function do not significantly differ if the weak or the strong correlation condition is enforced. In other words, the parameters of the state function do not yield a useful argument why the correlation criterion in one of its versions should be adopted or not. Instead, a useful argument will be the distribution function of residuals (Figs. 9 and 11).

The processed data minus the stations that violate the strong correlation criterion will be referred to as the selected data (identical to the last column of Table 2).

\subsection{Eventual database of present snowline climatology}

The specification of the data input and subsequent data flow for the present evaluation may now be summarized as follows:

- The fundamental data are station-observed snow depth $h\left(\theta^{* *}, x^{* *}, y^{* *}, z^{* *}\right)$ and externally provided CRU temperature $T\left(\theta^{*}, x^{*}, y^{*}, z^{*}\right)$.

- $\theta^{* *}$ is the time with daily resolution, $\theta^{*}$ is the time with monthly resolution, and $\theta$ is the time with annual resolution.

- $\quad x^{* *}, y^{* *}, z^{* *}$ are the space coordinates of the available climate stations; $x^{*}$ and $y^{*}, z^{*}$ are the space

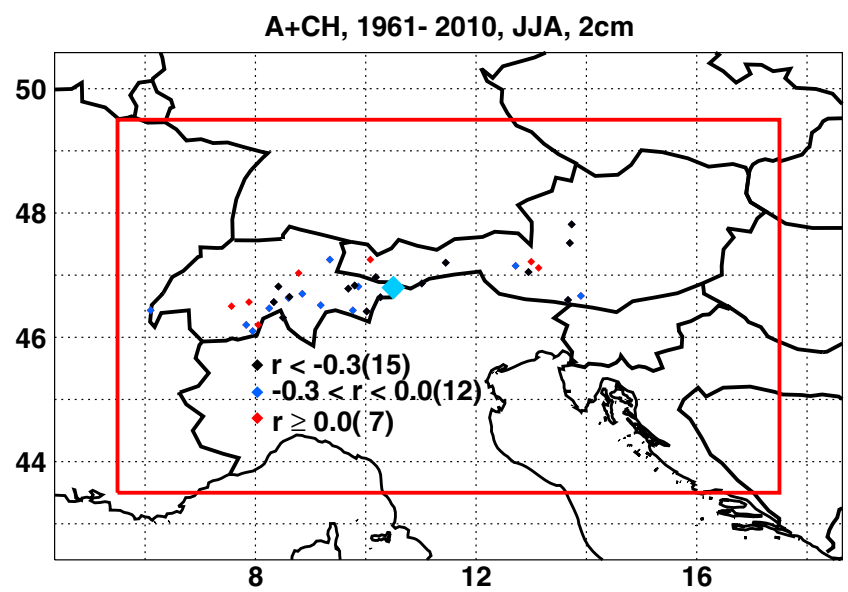

Fig. 5 Like Fig. 4, but for summer (JJA) 
coordinates of the CRU grid points; and $x, y$, and $z$ are the space coordinates of the selected climate stations.

- Processed data are unsaturated snow duration $n\left(\theta, x^{* *}, y^{* *}, z^{* *}\right)$, as well as European temperature $T(\theta)$ obtained by averaging $T\left(\theta^{*}, x^{*}, y^{*}, z^{*}\right)$ over the CRU grid points; they yield the processed data vector $\left\{n\left(\theta, x^{* *}, y^{* *}, z^{* *}\right), T(\theta), x^{* *}, y^{* *}, z^{* *}\right\}$.

- Selected data are snow duration $n(\theta, x, y, z)$ data that observe the strong correlation criterion, and European temperature $T(\theta)$; these together yield the selected data vector $\mathbf{D}=\{n(\theta, x, y, z), T(\theta), x$, $y, z\}$. D consists of five columns and 3,463 (447) rows for winter (summer).

- With D, we enter the model evaluation (see the next section and Appendix 1) which yields the parameter vector $\mathbf{Q}=\left(s_{0}, \tau_{0}, a, b, c\right)$; it consists of five columns and one row.

\subsection{Fitting algorithm}

An innovative ingredient of this study is the numerical fitting procedure to obtain the parameter vector $\mathbf{Q}$ for the state function. In our recent work (papers I-III and also in Hantel and Maurer (2011)), we have followed the strategy to minimize the cost function defined as the mean quadratic difference between the observed snow duration and the model state function; the errors were estimated with the bootstrap method (Efron and Tibshirani (1998)). Limitation of this standard strategy is that the difference between the observed snow duration and the model state curve is not normally distributed.

When the observations become rectified with the inverse state function, however, these rectified observations can then be modeled with the rectified state function which boils down to a linear regression problem; the corresponding distribution of the eventual residuals of the response variable should be automatically normal (not demonstrated here but we have checked that). A comprehensive description of the so-called generalized linear models can be found in Fahrmeir and Tutz (2001). The formal details of our present approach are summarized in Appendix 1. The results are not significantly different compared with our earlier results. The main progress of the new linear fitting procedure (as we call it, compared to our previous nonlinear procedure) is that we now have normally distributed "observations." This implies that the bootstrap method will not be required anymore; instead, the error estimate is available from the regression formulae. Further, we get a theoretically sound estimate of the explained

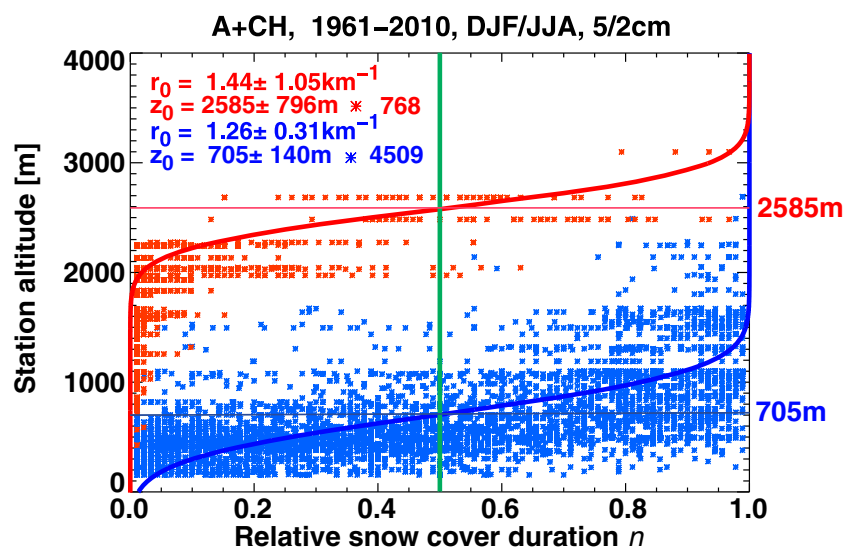

Fig. 6 Observed snow cover duration versus altitude. Data fitted with logistic model $P(z)=\Phi(\chi)$ with $\Phi=$ error function and $\chi=\sqrt{2 \pi} r_{0}\left(z-z_{0}\right) . r_{0}$ stands for the extreme slope of the fitted curve adopted at the abscissa value of $n=0.5$ and the ordinate value of $z=z_{0}$. One asterisk represents one station season. Parameters shown in inset, blue for winter (mean temperature $\left.T_{D J F}=0.3{ }^{\circ} \mathrm{C}\right)$, and $\mathrm{red}$ for summer $\left(T_{J J A}=17.1^{\circ} \mathrm{C}\right)$

variance. These estimates (see below) are consistently $50 \%$ and better which, in light of the amount of data (3,463 in winter and 447 in summer), make our subsequent results highly significant.

\section{Naive statistics}

We begin with some preliminary evaluations of the processed data; the correlation criterion is not yet applied and the model equations for $\tau$ and $N$ are not used. Rather, we apply standard statistical measures in order to obtain background parameters as a basis for later verification. For this purpose, we run, with the processed data vector $\left\{n\left(\theta, x^{* *}, y^{* *}, z^{* *}\right), T(\theta), x^{* *}\right.$, $\left.y^{* *}, z^{* *}\right\}$ just introduced, a couple of preliminary ("naive") evaluations.

\subsection{Snow duration versus altitude}

Figure 6 shows the simplest approach to obtain the snow lines: Plot the observed snow cover duration $n$ versus altitude $z$ in all years for the entire period, irrespective of the horizontal coordinates $x$ and $y$. Fit the data with a pertinent model and obtain every desired snow line. The fit curve $P(z)$ for $n$ must not be linear since $n$ is the mean of the binary stochastic variable $v$. For variables of this type, a logistic curve is the proper fitting function (Hosmer and Lemeshow (2000)). Out of the class of logistic curves (Mazumdar (1999)), we take 
here the error function. ${ }^{3}$ This type of plot requires only snow and altitude data, no temperature. It is identical to the original snowline determination of Hantel and Maurer (2011) (Fig. 2).

Also drawn in Fig. 6 are the median snow lines for the extreme seasons. The altitude $H$ is equal to the reference parameter $z_{0}$ of the interpolating error function (see legend of Fig. 6). $z_{0}$ represents the altitude of the extreme slope of the fitting curve. We find $705 \mathrm{~m}$ in winter and 2,585 $\mathrm{m}$ in summer. This allows to calculate the ratio

$\frac{\Delta H}{\Delta T}=\frac{2,585 \mathrm{~m}-705 \mathrm{~m}}{17 \cdot 1^{\circ} \mathrm{C}-0.3^{\circ} \mathrm{C}}=112 \frac{\mathrm{m}}{{ }^{\circ} \mathrm{C}}$.

This is the simplest approach to obtain an estimate of the temperature sensitivity of the snow lines. It may be compared with the result $166( \pm 5) \mathrm{m} /{ }^{\circ} \mathrm{C}$ which we will find below from the complete model evaluation.

\subsection{Snow duration versus temperature}

The next obvious naive diagram (not shown in this paper) is to plot $n$ against temperature, either for station temperature $t$ (Fig. 1 of paper III) or for European temperature $T$ (Fig. 4 of paper I). Note, however, that $n$ values from different climate stations can be lumped together into the same $n, t$ plot but not into the same $n, T$ plot because $n, T$ plots are generally different for different climate stations.

On the other hand, $t$ and $T$ are linearly correlated for different climate stations with about the same slope (Fig. 6 of paper III). This is the reason why $t$ can be replaced in our model through the mountain temperature.

\subsection{Distribution of $n$-trend estimates}

Figure 7 shows the simplest approach to obtain an estimate of the time trend of the snow duration. Following the method of pairwise slopes (Dery et al. (2005) as done in Gottfried et al. (2011)), we use all possible time trend estimates in the vicinity of the median snow line to get the pdf of the trend of the median snow duration. There is a faint indication of a negative trend (i.e.,

\footnotetext{
${ }^{3}$ Choice of the error function has been convenient in our programming but is not mandatory here. Since we do not yet apply our model of Fig. 6, one could take other logistic functions for the interpolation as well; the altitudes of the snow lines would then become dependent upon the logistic function chosen.
}
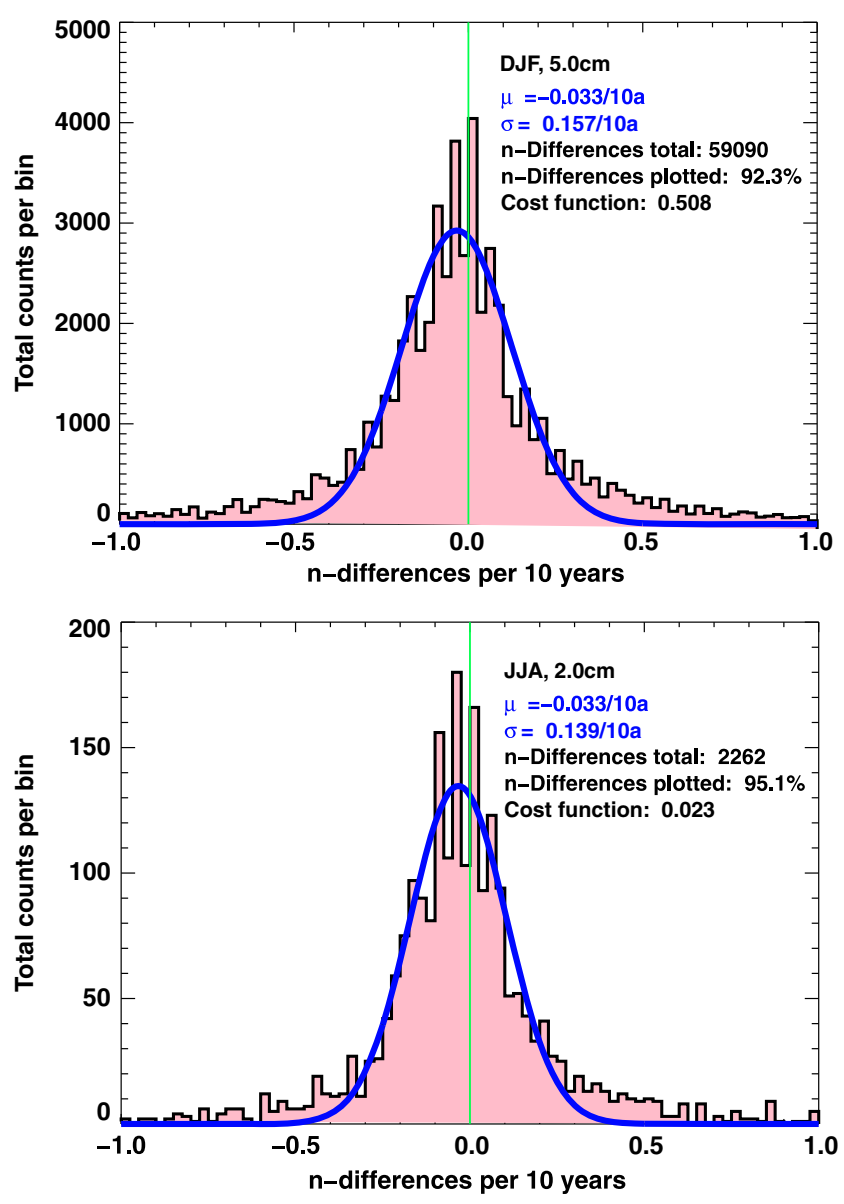

Fig. 7 Frequency distribution of trend estimates implicit in observed time series of snow duration. Data assembled in bins of width $0.025 / 10$ years. Total number of $n$ differences is proportional to area of the curve. Median $\mu$ and standard deviation $\sigma$ of Gaussian given in inset. Individual trend data taken from altitude interval $H \pm D / 2$. Data from processed Austrian and Swiss climate stations, winters and summers 1961-2010. Abscissa drawn is restricted to interval $\pm 1 / 10$ years; therefore, somewhat less than $100 \%$ of $n$ differences available are plotted

$-3.3 \% / 10$ years, equivalent to a reduction of 3 days of snow cover duration per 10 years, both for winter and summer), as expected from global warming. However, the trend in Fig. 7 over the 50 years 1961-2010 is largely insignificant, in both seasons. Note that all processed station seasons have been used for the pdf.

\section{Snowline climate of the Alps 1961-2010}

The snowline climate of the Alps is eventually condensed into the state function $N(\tau)$ of snow duration. The state function boils down the Alpine-wide 19612010 snow duration information from 3,463 station win- 


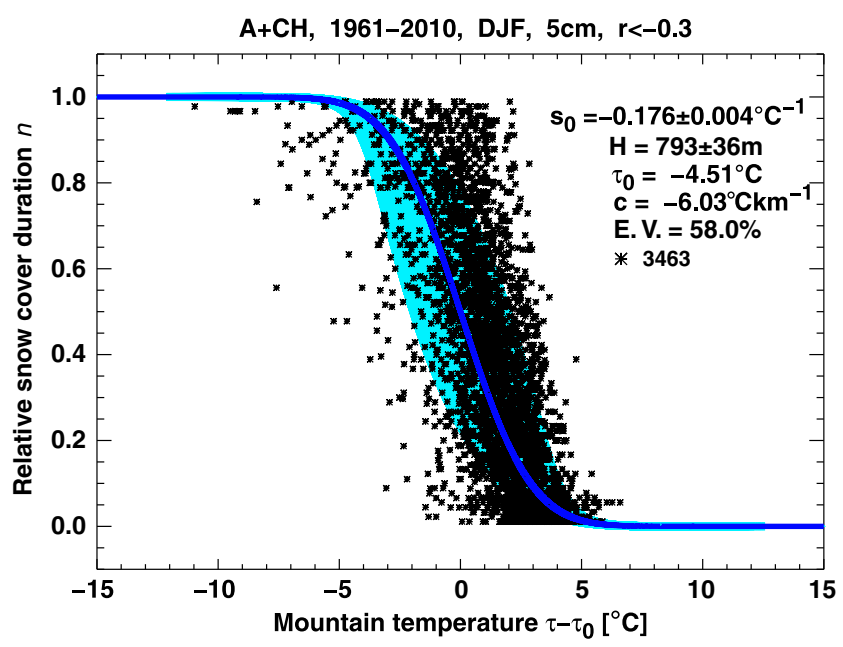

Fig. 8 Winter snow duration $n$ at 91 Austrian and Swiss climate stations plotted versus mountain temperature. Thick curve $N(\tau)$ is the state function of $n$. Each asterisk represents one out of 3,463 station winters. Colored shading captures $68 \%$ of data points (corresponding to one standard deviation in $\tau$ direction). Selected parameters are shown in the inset (E.V., explained variance)

ters (447 station summers) into one parameter vector that consists of just five numbers for each season. This data reduction is the essential added value of the present snowline model.

\subsection{State functions of snow duration for winters and summers in 1961-2010}

Figure 8 shows $N(\tau)$ for winter; the corresponding parameters are listed in the second column of Table 3 . They reproduce, by and large, the parameters ${ }^{4}$ of the all-Alps state curve as obtained for the shorter period 1961-2000 (Figs. 6 and 8 of Hantel and Maurer (2011)). For example, we find for the snow duration sensitivity $s_{0}=-0.18( \pm 0.004){ }^{\circ} \mathrm{C}^{-1}$ while Hantel and Maurer (2011) reported $s_{0}=-0.17( \pm 0.01){ }^{\circ} \mathrm{C}^{-1}$. In light of the different data and the different evaluation procedure, this must be considered a robust result.

The scatter of the data in Fig. 8 should be Gaussian in $\tau$ direction since observed temperature fluctuations are about normally distributed. Figure 9 demonstrates that the pdf is indeed normal. Main reason for this desirable result is that we have excluded the snow duration data which violate the correlation criteria; including these

\footnotetext{
${ }^{4}$ All error estimates in this paper are given as one standard deviation.
}

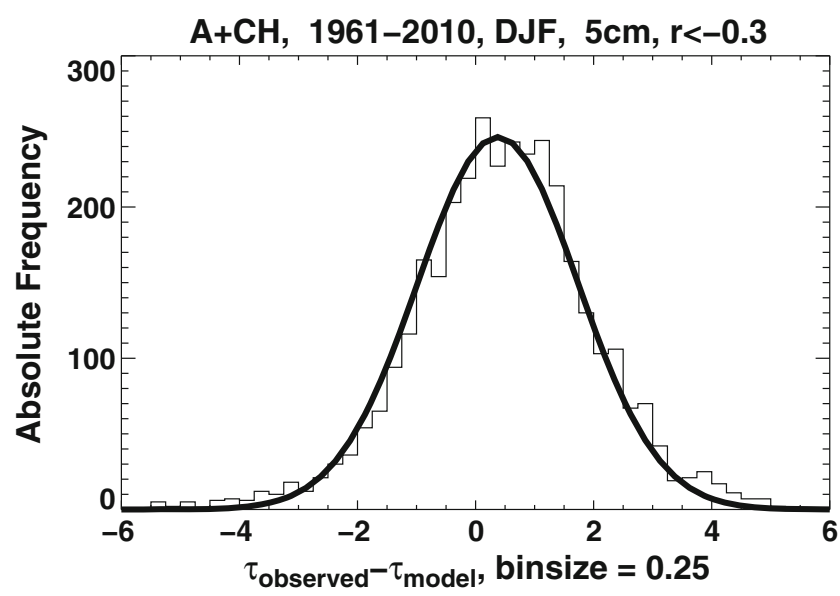

Fig. 9 Frequency distribution of deviations between observed mountain temperature and modeled mountain temperature $\tau$ in Fig. 8. Histogram fitted with normal distribution. Abscissa of maximum $=0.38$

would destroy the normality of the pdf in Fig. 9 (not demonstrated here). The observed and modeled mountain temperatures in Fig. 9 are defined as

$\tau_{\mathrm{obs}, \mathrm{i}}=T_{i}+a x_{i}+b y_{i}+c z_{i} ; \quad \tau_{\bmod , \mathrm{i}}=N^{-1}\left(n_{i}\right)$.

The input data $\left(n_{i}, T_{i}, x_{i}, y_{i}, z_{i}\right)$ are valid for one specific station season (index $i$ ); the components of the parameter vector $\mathbf{Q}$ implicit in $\tau_{\mathrm{obs}}$ and in $N^{-1}$ are from the fit for winter. Note that the normality of Fig. 9 is achieved without station temperature information; further, it is not enforced by the fitting routine.

The latter result may be summarized by saying that the snow duration preserves the information of local temperature. This is supported by the parameter $c$ which represents the vertical lapse rate of temperature. The estimates for $c$ in Table 3 come close to the observed mean value $\left(c=-6.5{ }^{\circ} \mathrm{C} / \mathrm{km}\right.$ in the standard atmosphere; see, e.g., Reuter et al. (2001), p. 166). The parameter $-1 / c$ in Table 3 is given by the formula in Eq. (9) which shows the temperature sensitivity of the altitude of the snow lines (not just of the median snow line but of all snow lines). Its value in winter in Table 3, second column, is $166 \mathrm{~m} /{ }^{\circ} \mathrm{C}$. This result compares favorably with the estimate of $150 \mathrm{~m} /{ }^{\circ} \mathrm{C}$ reported by Beniston (2010) and also compared with the preliminary estimate of $112 \mathrm{~m} /{ }^{\circ} \mathrm{C}$, which we have found in Fig. 6 according to Eq. (12).

The first three columns of Table 3 allow to compare the impact of the threshold in winter. Using the $3 \sigma$ criterion for significance, the difference between the para- 
Table 3 Parameters of snow duration state function, period 1961-2010, A + CH, selected input data

\begin{tabular}{lllll}
\hline & DJF & DJF & DJF & JJA \\
& $2 \mathrm{~cm}$ & $5 \mathrm{~cm}$ & $10 \mathrm{~cm}$ & $-0.08( \pm 0.01)$ \\
\hline$s_{0}\left({ }^{\circ} \mathrm{C}^{-1}\right)$ & $-0.18( \pm 0.004)$ & $-0.18( \pm 0.004)$ & $-0.14( \pm 0.005)$ & $-7.96( \pm 2.65)$ \\
$\tau_{0}\left({ }^{\circ} \mathrm{C}\right)$ & $-3.72( \pm 0.12)$ & $-4.51( \pm 0.14)$ & $-6.96( \pm 0.27)$ & $0.65( \pm 0.12)$ \\
$a\left({ }^{\circ} \mathrm{C} /{ }^{\circ} \mathrm{lon}\right)$ & $-0.22( \pm 0.01)$ & $-0.21( \pm 0.01)$ & $-0.28( \pm 0.02)$ & $-3.61( \pm 0.61)$ \\
$b\left({ }^{\circ} \mathrm{C} /{ }^{\circ} \mathrm{lat}\right)$ & $-0.24( \pm 0.06)$ & $0.01( \pm 0.07)$ & $-13( \pm 0.09)$ & $-8.14( \pm 1.2)$ \\
$c\left({ }^{\circ} \mathrm{C} / \mathrm{km}\right)$ & $-6.10( \pm 0.18)$ & $-6.03( \pm 0.19)$ & $913( \pm 49)$ & $1,472( \pm 299)$ \\
$D(\mathrm{~m})$ & $865( \pm 32)$ & $887( \pm 36)$ & $974( \pm 55)$ & $3,083( \pm 1121)$ \\
$H(\mathrm{~m})$ & $654( \pm 28)$ & $793( \pm 36)$ & $135( \pm 6)$ & $123( \pm 18)$ \\
$-1 / c\left(\mathrm{~m} /{ }^{\circ} \mathrm{C}\right)$ & $164( \pm 5)$ & $166( \pm 5)$ & 52 & 50 \\
E.V. $(\%)$ & 61 & 58 & & \\
\hline
\end{tabular}

First three columns for winter (three different thresholds of snow depth), last column for summer. First five parameters: components of parameter vector $\mathbf{Q}$, defined in the last point of Section 3.7. For definition of $D$ and $H$, see Eqs. 7 and 8

E.V. explained variance of linear parameter fit

meters of the first two columns is not significant. Thus, our estimates of the temperature sensitivity (parameter $s_{0}$ ) and of the median snowline altitude (parameter $H$ ) appear to be robust; this has earlier been demonstrated for the threshold interval 1-4 cm of summer (see Table S5 of the supplementary data of Gottfried et al. (2011)).

Our quantities $D$ and $H$ for summer (fourth column of Table 3) can be compared with Gottfried et al. (2011) (Fig. 5, second column). The present estimates are not significantly different from their estimates (they find $D=992 \mathrm{~m}, H=2.897 \mathrm{~m}$ ).

This brings us to Fig. 10 which shows the state function of snow duration for summer. ${ }^{5}$ Since the data situation for summer is considerably poorer than for winter (only about a tenth of station seasons were available, the position of observed data was below the median snow line), the parameters are considerably less accurate. This is also seen in Fig. 11. The deviation of the mountain temperature from the fitted curve has an approximate Gaussian profile indeed but gets shifted to the right of zero. This effect must be attributed to a systematic bias towards warm temperatures in Fig. 10 due to climate stations at low (and consequently relatively warm) altitudes with comparatively long snow duration caused by winter snow which still has not melted. This systematic effect is virtually absent in winter.

\footnotetext{
${ }^{5}$ The shading in Figs. 8, 10 is constructed as follows: For an arbitrary $n$ the width of the shading in $\tau$-direction is made proportional to $(1-n) n$ which is the theoretical variance of a Bernoullidistributed quantity like the snow cover duration. The factor of proportionality is chosen such that $68 \%$ of all data points fall into the shaded area.
}

5.2 Snowline surfaces for winters and summers in 1961-2010

The altitude of a snow line $n$ has been defined above in the formula in Eq. 8. The corresponding mountain temperature is specified through the inverse of the state function as $\tau(n)=N^{-1}(n)$. For example, for $n=$ 0.5 , the fitted $N$ from Fig. 8 yields $\tau=\tau_{0}=-4.51{ }^{\circ} \mathrm{C}$. The snow line altitude $H(x, y)$ according to Eq. 8 is $a$ planar surface that penetrates across the orography of the Alps; the snow line is generated by the cut between the surface and the orography. Physically, the function $H(x, y)$ is an isothermal surface defined by constant $\tau$.

Shown in Fig. 12 is the median snow line of winter. It is similar to the winter snowline pattern as published recently by Hantel and Maurer (2011). The difference

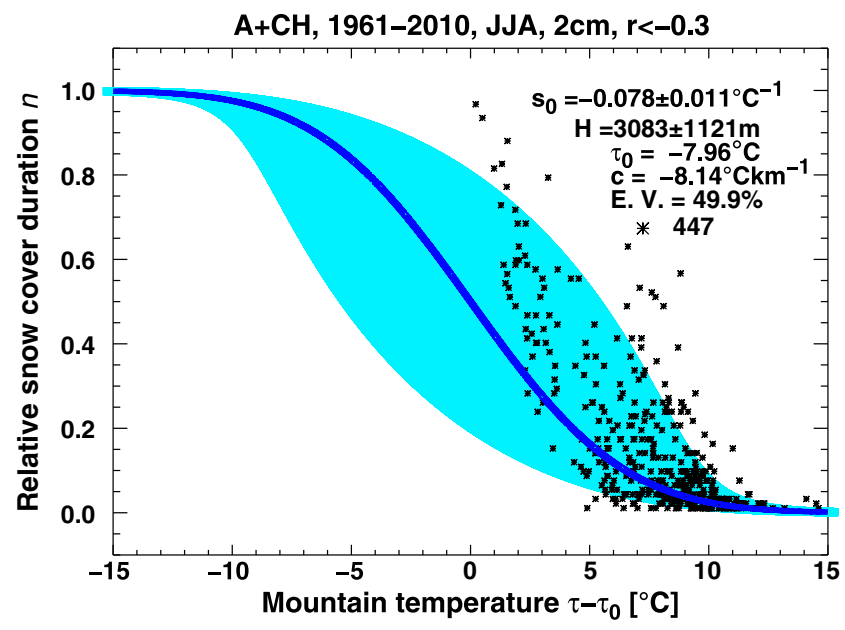

Fig. 10 As Fig. 8, but for summer (15 Austrian and Swiss climate stations, 447 station summers) 


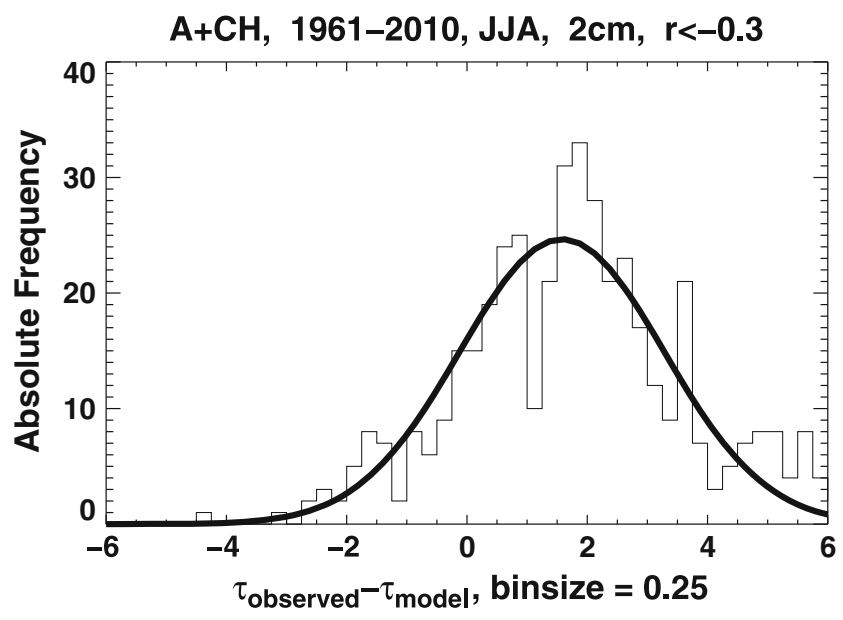

Fig. 11 Frequency distribution of deviations between observed mountain temperature and modeled mountain temperature $\tau$ in Fig. 10. Histogram fitted with normal distribution. Abscissa of maximum $=1.58$

is the database (all Alps 1961-2000 originally, $\mathrm{A}+\mathrm{CH}$ 1961-2010 here). The mean altitude $(793 \mathrm{~m})$ is larger than before $(641 \mathrm{~m})$; the west-east slope $\left(-35 \mathrm{~m} /{ }^{\circ}\right.$ longitude) is smaller than before $\left(-56 \mathrm{~m} /{ }^{\circ}\right.$ longitude $)$. In light of the error of the parameters, the present and the earlier estimates are not significantly different.

The snow lines for higher snow probabilities are located above the median snow line. For example, the altitude of the snow line $90 \%$ is about $500 \mathrm{~m}$ higher than the median snow line (plot not reproduced). This quantifies the altitude difference for different snow lines.
Figure 13 shows the median snow line for summer. Its mean altitude of $3,083 \mathrm{~m}$ indicates that snow cover probability in summer is restricted to the highest summits. This result, well in accord with general experience, may be useful for ecological purposes (Gottfried et al. (2011), their estimate of the median snow line altitude is $2,897 \mathrm{~m}$ ). Since the database in summer is considerably smaller than in winter, the parameters of the snow line in summer have a limited significance.

While Fig. 12 represents the mean winter snowline conditions in the Alps for the period 1961-2010, we can also ask for the mean position in individual years, simply by picking the actual $T$ in the mountain temperature for the specific year. In warm winters, the snowline surface rises; in cold winters, it sinks. The cutting of the snowline surface (i.e., the plane marked by the red boundary) across the topography of the Alps (i.e., the white circumference) generates a corresponding change of the snow-covered surface from year to year (i.e., the gray surface in Figs. 12 and 13). The time series of this area is drawn in Fig. 14 through implementing $T$ of the actual year into Eq. 8. For example, the cold winter in 1963 showed about 2.4 times the mean area above the median snowline surface. Conversely, the warm winter in 2007 showed just $55 \%$ of the mean area of $133,500 \mathrm{~km}^{2}$.

\section{Extension into individual valleys}

With due caution, the snow lines can be used to illustrate the snow cover situation of individual Alpine

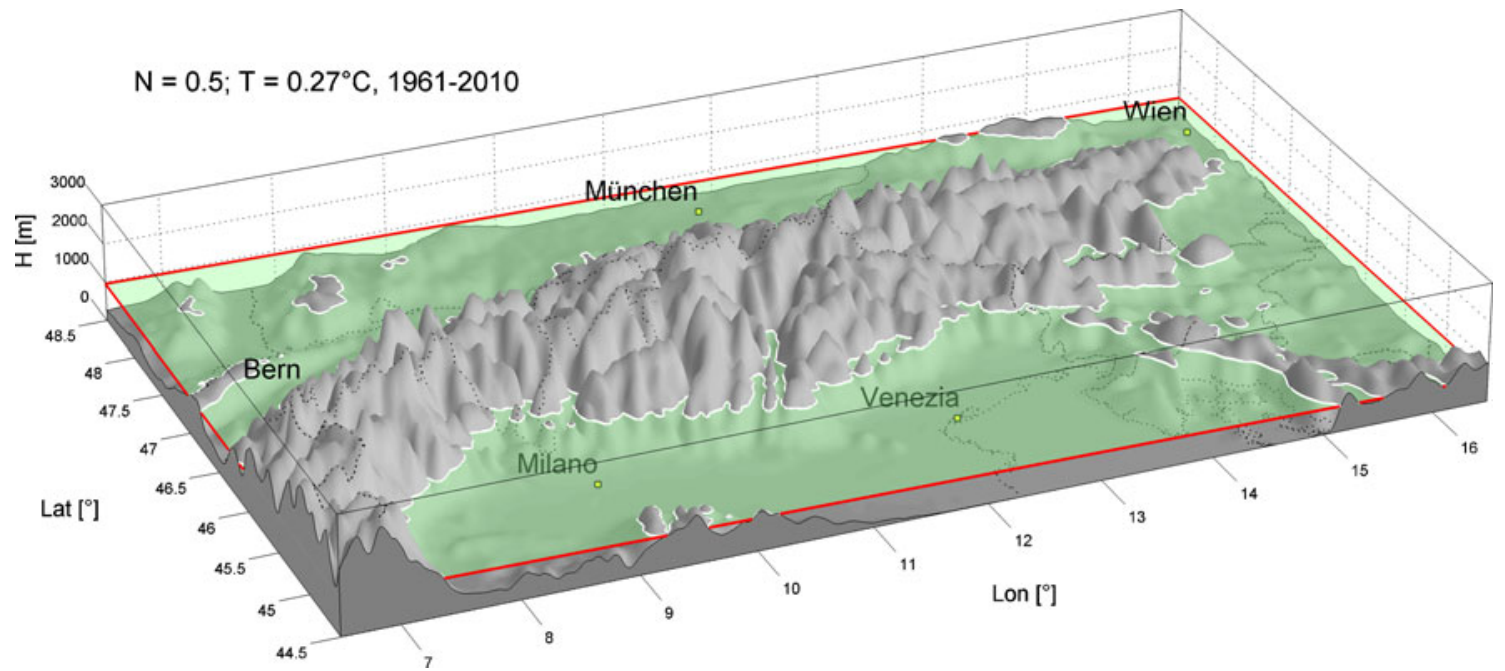

Fig. 12 Winter snow line $50 \%$, mean altitude $793 \mathrm{~m}$. Drawn (red circumference) is planar surface $H(0.5, T, \lambda, \varphi)$ according to the formula in Eq. 8 for fixed $\tau=N^{-1}(0.5)=\tau_{0}=-4.51^{\circ} \mathrm{C}$ and fixed European temperature $T=0.27^{\circ} \mathrm{C}$. The median snow line (white circumference) is intersection with orography 


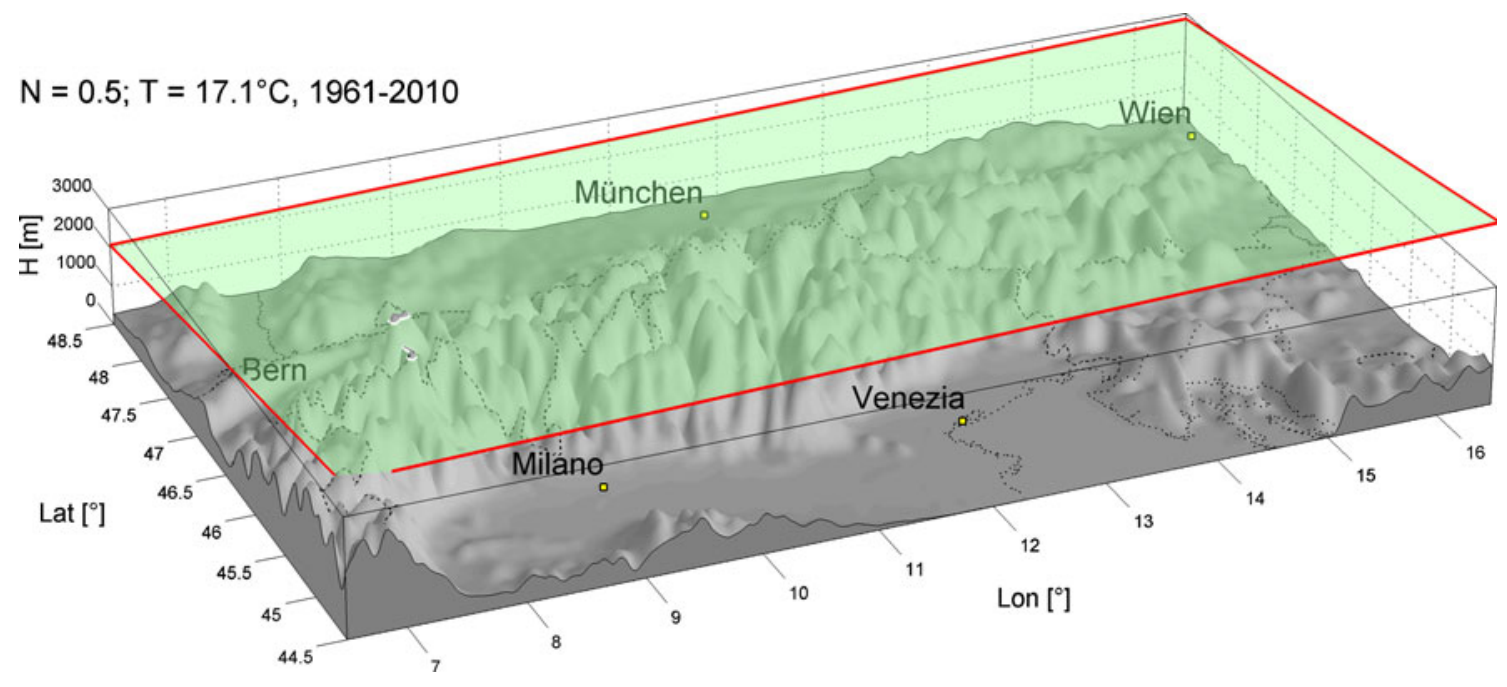

Fig. 13 Summer snow line $50 \%$, mean altitude $3,083 \mathrm{~m} . \tau_{0}=-7.96{ }^{\circ} \mathrm{C}, T=17.1^{\circ} \mathrm{C}$

valleys. Figure 15 demonstrates how the Alpine mean snow lines in 1961-2010 cut across the mountains around the climate station Innsbruck. The transition from snow probability 30 up to $95 \%$ can be seen in the immediate vicinity of the climate station because the surrounding orography maps the snow lines over this large interval.

We would expect that the mean snowline surface, valid for the Alps, cannot possibly coincide with the actual snow situation in Innsbruck. In order to quantify the anticipated systematic and stochastic shift, we define the equivalent altitude $H^{*}$ of Innsbruck. $H^{*}$ is gained by projecting the relative snow duration $n$, measured in Innsbruck in each individual year, upon the state curve in Fig. 8; the emerging value of $\tau$ on the abscissa is then transformed into $H^{*}$ through the formula in Eq. 8, plus using the coordinates $x$ and $y$ of Innsbruck and the European temperature $T$ of the individual year. The values of $H^{*}$ for individual years obtained in this manner are plotted in Fig. 16. The mean equivalent altitude is higher than the true altitude $h$ of the station. This implies that the mean snow situation of Innsbruck is somewhat underestimated by our Alpine fit: The true snow cover at this station is such as if the station would be located $128 \mathrm{~m}$ higher. This is equivalently visible in the mean observed versus modeled snow cover duration in 1961-2010 in Innsbruck: $\bar{n}=$ 0.42 versus $\bar{N}=0.33$.

This difference is in accord with the accuracy of the parameters that specify the state function $N(\tau)$.
Fig. 14 Time series of area in the Alps that is at least $50 \%$ snow covered (winters in 1961-2010). Area plotted as percentage of area that is located at or above the 50 -year mean position of the median snow line (i.e., $133,500 \mathrm{~km}^{2}$ )

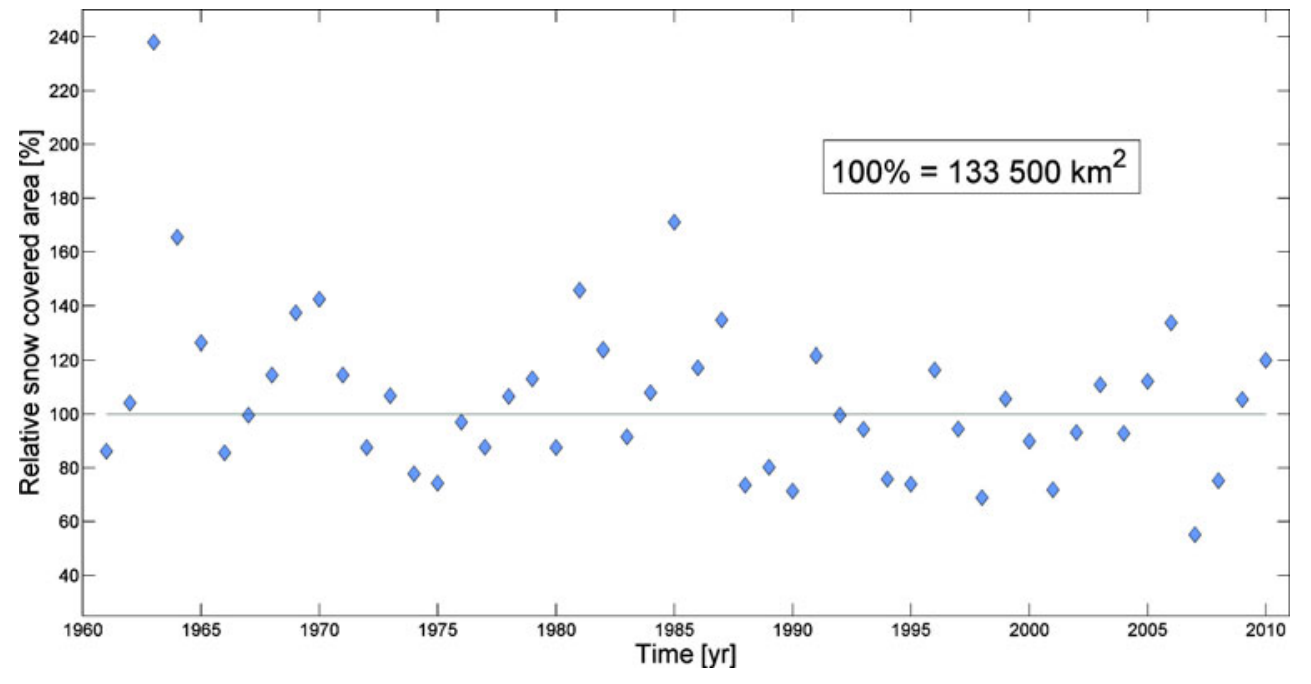




$\begin{array}{lll}\mathrm{N}>0.75 & 0.5<\mathrm{N}<0.75 & \mathrm{~N}<0.5 \\ & & \mathrm{~T}=0.27^{\circ} \mathrm{C}, \text { Winter } 1961-2010\end{array}$

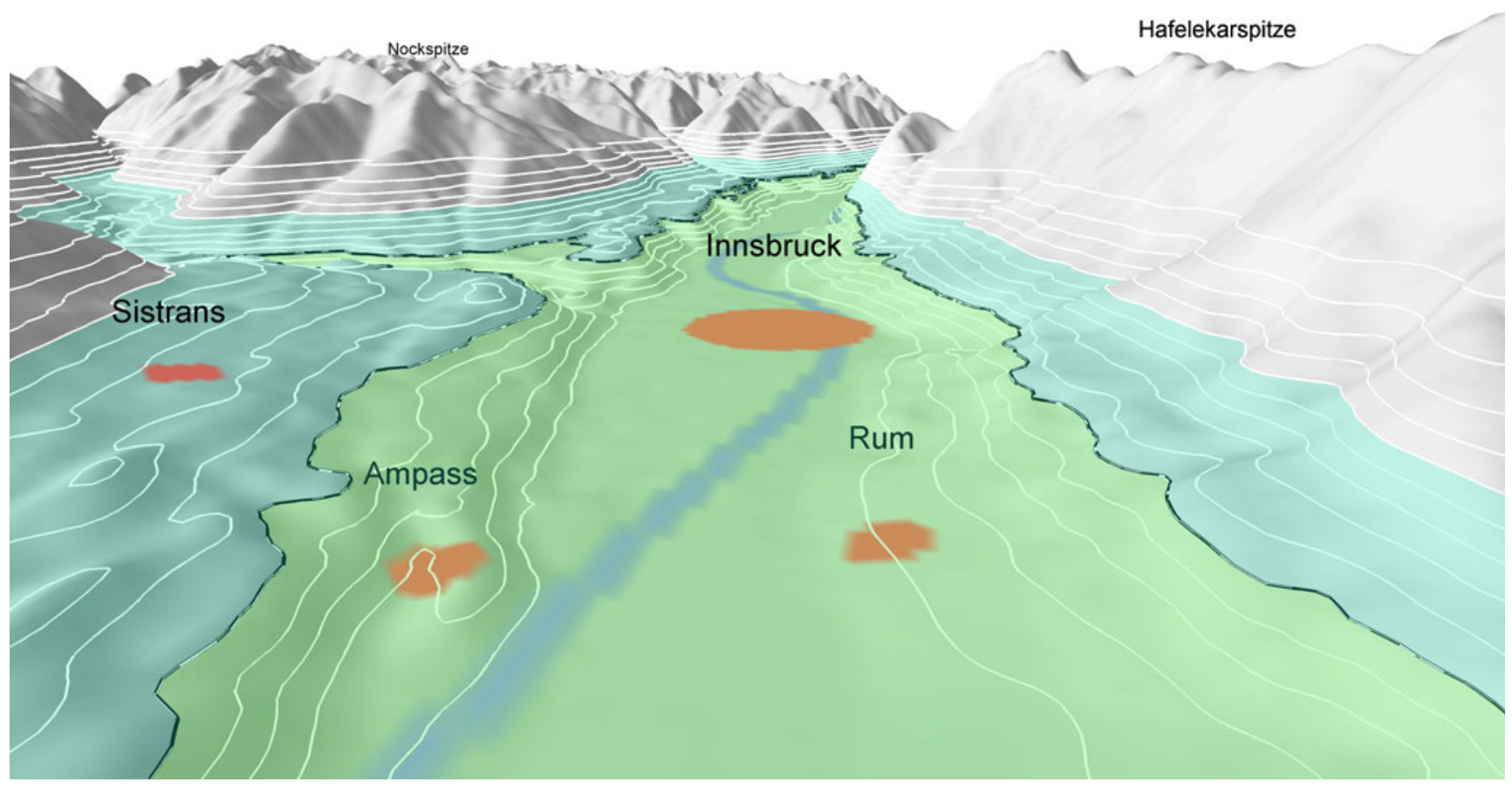

Fig. 15 View from the east towards climate station Innsbruck. Mean snow lines drawn from $30 \%$ upward, increment $5 \%$, up to $95 \%$; median snow line (climate average in 1961-2010) in black

Fig. 16 Time series of equivalent altitude $H^{*}$ for Innsbruck. For definition of $H^{*}$, see text

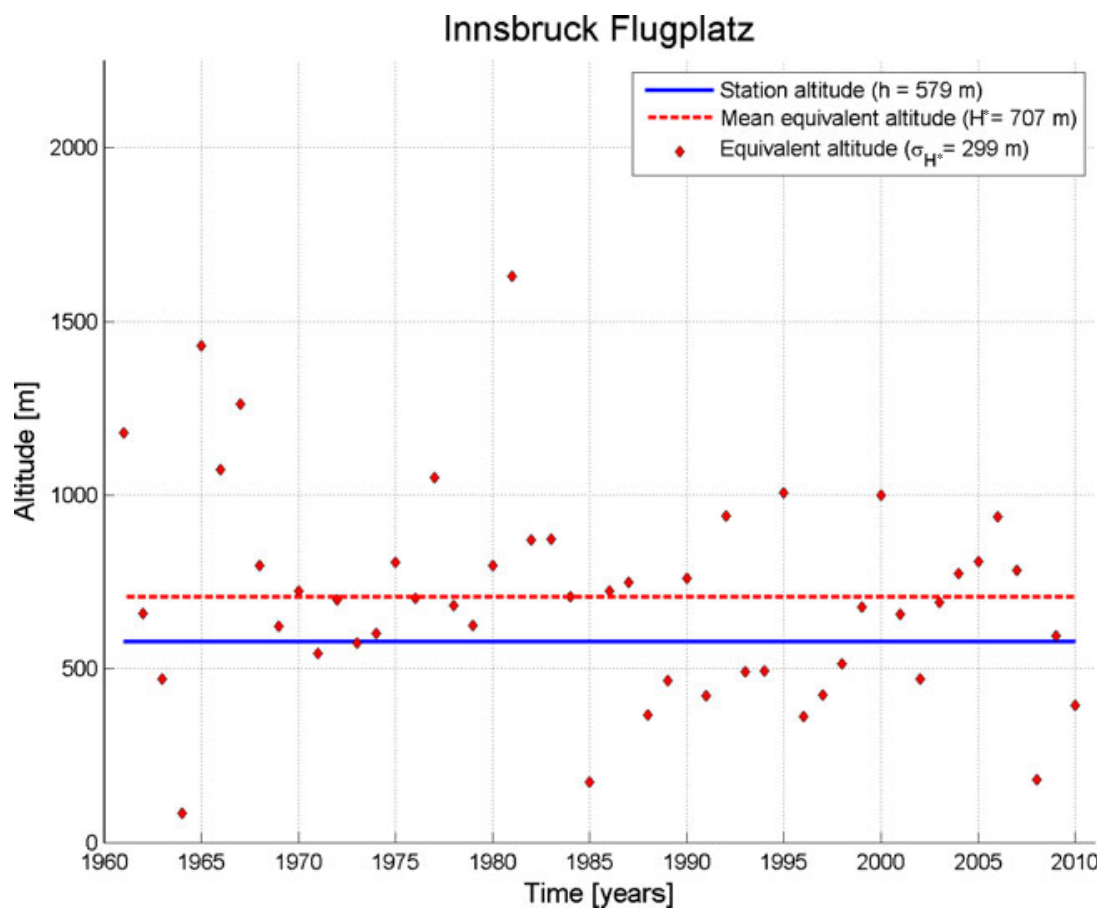


Other climate stations in our database have also been investigated. Ten of them have been selected. The small difference between $H^{*}$ and $h$ (last column in Table 4) indicates that the mean snow line altitude is quite well reproduced over the entire epoch in 19612010 for most of the selected stations. None of the differences is statistically significant; in other words, $H^{*}$ and $h$ are statistically equal. The sizeable scatter from year to year (as indicated by $\sigma_{H^{*}}$ ) demonstrates that only the climatological mean is acceptably reproduced by our evaluation whereas individual years may show appreciable deviation between implied and true station altitude.

\section{Trend of snow lines}

The climate epoch in 1961-2010 is characterized by climate warming which can also be found in the snow cover. The fact that the snowline climate of the Alps is externally controlled by the European temperature in our model allows to estimate trends of snow cover duration and of snowline altitude, provided that the time trend of the European temperature is specified externally.

We adopt here the trend $\mathrm{d} T / \mathrm{d} \theta=(0.30 \pm 0.17)^{\circ} \mathrm{C} / 10 \mathrm{a}$ of the CRU temperature for 1961-2010. The previous estimate for the winters of the 40-year period 19612000 used in Hantel and Maurer (2011) had been $\mathrm{d} T / \mathrm{d} \theta=(0.44 \pm 0.32){ }^{\circ} \mathrm{C} / 10 \mathrm{a}$; note the instability of these figures against changing the database. With the present trend estimate, using formulae Eqs. 10 and 11, we find for winter the following equations:

$\frac{\partial N}{\partial \theta}=-0.054( \pm 0.031) / 10 \mathrm{a} ; \quad \frac{\partial H}{\partial \theta}=50( \pm 28) \mathrm{m} / 10 \mathrm{a}$.

The first figure is to be compared with the estimate $\Delta n / \Delta \theta=-(0.033 \pm 0.157) / 10 \mathrm{a}$ in Fig. 7 ; both are sta- tistically equal. The estimate for the trend of $N$ applies at the altitude of the median snow line, i.e., it is the extreme trend of $N$ in the entire field; above and below the median snow line, it decreases gradually to zero, with half-width $D$. Conversely, the trend of $H$ as represented by the second figure of Eq. 14 is valid for all snow lines from 0 to 1 . It is directed upward but numerically weak. Equivalent calculations can be made with $\mathrm{d} T / \mathrm{d} \theta=(0.34 \pm 0.13){ }^{\circ} \mathrm{C} / 10$ a for summer (adopt $s_{0}$ and $c$ in Table 3) with about the same result.

Both estimates in Eq. 14 point into the expected direction: The snowcover duration decreases and the snowline altitude increases under the influence of global warming. However, the estimates are insignificant because the external temperature trend is insignificant.

A further trend, indirectly made visible by the snow lines, is the trend of the relative area above the median snow line adopted in individual years. It can be deduced from Fig. 14 and shows an insignificant decrease of $-7.0( \pm 4.1) \% / 10$ a.

Another application of our model would be to forecast the likely snow duration of the next season. Applications of that kind are principally possible with the output of present numerical weather prediction models but at present have a limited value due to the comparatively poor performance of seasonal temperature forecasts $T$ for Europe. By specifying the desired snow line (e.g., the median snow line $n=0.5$ ) and inserting it, together with the seasonal forecast of $T$, into formula Eq. 8, we would get the sloping surface $H(n, T, x, y)$ for the Alps in the season ahead.

\section{Final remarks, conclusions, and outlook}

The present study of the snowline climatology of the Alps has been based on the intuitive concept of the snow limit. This notion of snow research reaches
Table 4 Mean equivalent altitude $H^{*}$ and corresponding standard deviation $\sigma_{H^{*}}$ for selected stations

\begin{tabular}{lcrllllr}
\hline Station name & $h(\mathrm{~m})$ & \multicolumn{1}{c}{$\lambda\left(^{\circ}\right)$} & $\varphi\left(^{\circ}\right)$ & \multicolumn{1}{l}{$r$} & $H^{*}(\mathrm{~m})$ & $\sigma_{H^{*}}(\mathrm{~m})$ & $H^{*}-h(\mathrm{~m})$ \\
\hline Wien-Hohe Warte & 203 & 16.35 & 48.25 & -0.75 & 295 & 253 & 92 \\
Grono & 382 & 9.15 & 46.25 & -0.51 & 363 & 271 & -19 \\
Salzburg Airport & 430 & 13.00 & 47.80 & -0.80 & 493 & 202 & 63 \\
Bregenz & 436 & 9.75 & 47.50 & -0.70 & 569 & 237 & 133 \\
Neuchatel & 487 & 6.95 & 47.00 & -0.66 & 338 & 263 & -149 \\
Bad Ragaz & 496 & 9.50 & 47.02 & -0.60 & 650 & 249 & 154 \\
Chur-Ems & 555 & 9.53 & 46.87 & -0.45 & 662 & 318 & 107 \\
Innsbruck Airport & 579 & 11.35 & 47.25 & -0.54 & 707 & 299 & 128 \\
Adelboden & 1,320 & 7.57 & 46.50 & -0.36 & 1510 & 432 & 190 \\
La Dole & 1,670 & 6.10 & 46.43 & -0.41 & 1694 & 435 & 24 \\
Villacher Alpe & 2,140 & 13.67 & 46.60 & -0.33 & 1666 & 296 & -474
\end{tabular}


far into meteorology (Steinacker (1983)), hydrology (Bloeschl and Sivapalan (1995)), climatology in general (Hann (1883); Hann (1908)), mountain weather and climate (Barry (1992)), mountain biology and ecology (Körner (2003); Nagy and Grabherr (2009); Wipf et al. (2009)), and climate change (Karl and Trenberth (2003); Lemke et al. (2007); Clow (2010)), to name just a few fields.

Here, we have been interested in the length of time in a given season during which the snow on the ground exceeds a certain threshold. We have considered only the state component in the snow budget (i.e., the depth of the existing snow cover); this includes the tacit assumption that the measured snow cover is always in equilibrium with environmental temperature. Neither the flux component (i.e., the snow fall) nor the source component (the phase changes, i.e., the freezing/melting/evaporation processes at work in the snowpack) has been the subject of this study (for the terminology of state, flux, and source quantities in geophysical fluid budgets, see chapter 1 in the LandoltBörnstein volume on the climate at the earth's surface (see Hantel (2005)). Thus, the present model is only applicable on time scales well above the daily scale.

We have introduced the notion of the snow line by connecting places at which the probability to encounter snow has a certain fixed value. The snow probability of a season can vary between 0 ("never snow") and 1 ("always snow"). This includes the snow limit as the special probability of $50 \%$ for snow which constitutes the concept of the median snow line. Observational basis has been the daily snow depth data from the routine climate stations. Together with the mountain temperature, we have designed a model that compresses all quality-controlled seasonal snow probabilities $(3,463$ in winter, 447 in summer) into the state function $N(\tau)$ that is specified through just five Alpine-wide parameters. This is an enormous data reduction. Yet our model allows to derive from $N(\tau)$, through analytical means, various climatically relevant quantities. These include the temperature sensitivity of snow cover duration and snow line dynamics at all altitudes as well as the slope of the snow line surfaces in horizontal direction; further, they yield trend estimates.

Limitations of the present theory include the following:

- Snow amount is not necessarily correlated with snow cover duration. So one should be cautious in using the present results as implications that concern snow amount or snow height.

- The accumulation (snow fall) and ablation process (snow melt) is not explicitly included in the model.
What we imply is that the corresponding growing and decaying phases cancel each other in a more or less stochastic way. This is a first approximation at best.

- The eventual Alpine-wide parameter vector $\mathbf{Q}=$ $\left(\mathbf{s}_{\mathbf{0}}, \tau_{\mathbf{0}}, \mathbf{a}, \mathbf{b}, \mathbf{c}\right)$ cannot possibly reproduce the snow duration characteristics at a local climate station. So one should be cautious in interpreting the present results locally.

- The key hypothesis of this study has been that the most influential quantity that controls the snow duration is the seasonal mean of temperature, averaged over Europe. While this applies quite well for the dynamics of the median snow line, the limits of this hypothesis should be kept in mind. One should be particularly cautious in interpreting our results in altitudes far off the altitude of the median snow line.

The notion of the snow probability is yet applicable on the local scale in the field as well as on the regional scale. It can be extended to land surface observations from satellite, as evidenced by satellite pictures which show the daily snow limit as a sharp line. For example, the MODIS satellite maps, on a worldwide scale, map the snow limit with a ground resolution of $4 \mathrm{~km}$ (which can be downscaled to below 1-km resolution; see also NOAA/NESDIS/OSDPD/SSD (2004)). A recent application is the study of Kaur et al. (2010) in the Indian Himalayas. These authors use satellite measurements of monthly snow cover; the snow limit is specified as the location that separates snow-covered from snowfree areas.

This concept is also used by Parajka et al. (2010) who successfully try to estimate snow cover from MODIS satellite data during cloud cover. They introduce a regional snowline method to distinguish between land pixels and snow pixels and find, for example, the altitude of the snow line on 23 January 2003 at about $900 \mathrm{~m}$ (subjectively estimated from Fig. 3); this is $100 \mathrm{~m}$ above our 50-year winter average of the median snow line.

Satellite time series of the snow limit and of snow probability at the ground, up to now, are still too short for climate studies of several decades. It is for this reason that we have restricted the present 50-year study to station data input. However, remote observations from satellite have the potential to yield a completely uniform and homogeneous observational background. Thus, in the long run, snow and snowline quantities will presumably be studied on basis of remote satellite observations.

Acknowledgements Discussions with many colleagues (notably Roger Barry, Michael Gottfried, Georg Grabherr, Vanda Grubisic, Leopold Haimberger, Michael Kuhn, Christian Schönwiese, Peter Speth, Reinhold Steinacker) helped to clear the snowline concept. The Austrian Academy of Sciences has supported 
Table 5 Specifications of the nonlinear and the linear fit for the two different estimates $\mathbf{Q}^{\prime}$ and $\mathbf{Q}$ of the parameter vector

\begin{tabular}{lll}
\hline & Nonlinear fit & Linear fit \\
\hline Measured snow duration & $n_{i}$ & $\eta_{i}=\Phi^{-1}\left(n_{i}\right)$ \\
Variance & $\sigma_{n_{i}}^{2}=M\left(1-n_{i}\right) n_{i}$ & $\sigma_{\eta_{i}}^{2}=2 \pi M\left(1-n_{i}\right) n_{i} \exp \left(\eta_{i}^{2}\right)$ \\
Predictor & $\tau_{i} \rightarrow \chi_{i} \rightarrow \Phi\left(\chi_{i}\right)=\Phi_{i}$ & $\tau_{i} \rightarrow \chi\left(\tau_{i}\right)=\chi_{i}$ \\
Predictand & $n^{i}=\Phi_{i}$ & $\eta^{i}=\chi_{i}$ \\
Cost function $J\left(s_{0}, \tau_{0}, a, b, c\right)$ & $\sum_{i=1}^{i=I}\left(\frac{n_{i}-n^{i}}{\sigma_{n_{i}}}\right)^{2}$ & $\sum_{i=1}^{i=I}\left(\frac{\eta_{i}-\eta^{i}}{\sigma_{\eta_{i}}}\right)^{2}$ \\
Resulting parameter vector & $\mathbf{Q}^{\prime}=\left(s_{0}^{\prime}, \tau_{0}^{\prime}, a^{\prime}, b^{\prime}, c^{\prime}\right)$ & $\mathbf{Q}=\left(s_{0}, \tau_{0}, a, b, c\right)$
\end{tabular}

this research over the years in the Clean Air Commission and in the National Committee for the IGBP. The University of Vienna has funded the investigations through its Research Platform Program. Further, the Austrian Science Fund (FWF) has financially supported the study (Project P21335).

Open Access This article is distributed under the terms of the Creative Commons Attribution License which permits any use, distribution, and reproduction in any medium, provided the original author(s) and the source are credited.

\section{Appendix 1-Generalized linear model}

The estimate of the parameter vector $\mathbf{Q}=\left(s_{0}, \tau_{0}, a, b, c\right)$ for the state function $N$ rests upon the selected data vector $\mathbf{D}_{\mathbf{i}}=\left\{n_{i}, T_{i}, x_{i}, y_{i}, z_{i}\right\}$. The fitting algorithm of our model uses the function $\Phi$ as defined in Eq. 2. It constitutes a relationship between $n$ and $\chi$ as defined in Eq. 5; $\chi$ is a linear transformation of the mountain temperature, Eq. 4. We repeat here the corresponding formulae for convenience:

$$
\begin{aligned}
\Phi(\chi) & =\frac{1}{\sqrt{2 \pi}} \int_{\vartheta=-\infty}^{\chi} e^{-\vartheta^{2} / 2} \mathrm{~d} \vartheta ; \quad \chi=\sqrt{2 \pi} s_{0}\left(\tau-\tau_{0}\right) ; \\
\tau & =T+a x+b y+c z .
\end{aligned}
$$

Our theory consists in modeling the predictand $n$ with the multivariate predictor $\tau$ which again is calculated from the measured $(T, x, y, z)$. The measured $n$ can be used in two different modes:

Observed snow duration: $n_{i}$;

$$
\text { transformed snow duration: } \eta_{i}=\Phi^{-1}\left(n_{i}\right) \text {. }
$$

Both $n_{i}$ and $\eta_{i}$ represent the same observed snow duration, but both constitute different fitting modes: The nonlinear mode and the linear mode. Before discussing these, we consider the a priori error of $n_{i}$. Since the snow duration is Bernoulli distributed, the variance of $n_{i}$ is

$\sigma_{n_{i}}^{2}=M\left(1-n_{i}\right) n_{i}$, as noted in paper I; $M$ is a normalization constant. The variance of the transformed snow duration $\eta_{i}$ is then

$\sigma_{\eta_{i}}^{2}=2 \pi M\left(1-n_{i}\right) n_{i} \exp \left(\eta_{i}^{2}\right)$.

This relation follows from the slope of $\Phi$ along with Eq. 17. The nonlinear fit (see Table 5) yields the parameter vector $\mathbf{Q}^{\prime}$ through minimizing the cost function based on the observed $n_{i}$; the linear fit yields the parameter vector $\mathbf{Q}$ through minimizing the cost function based on the transformed $\eta_{i}$.

Both estimates $\mathbf{Q}^{\prime}$ and $\mathbf{Q}$ are principally different. Which one is better? In our previous work, we have used the standard estimate $\mathbf{Q}^{\prime}$. In the present study, we have switched to $\mathbf{Q}$. The linear fit has a considerably improved theoretical founding. Since the Gaussian error function $\Phi$ belongs to the family of responses with exponential probability density functions, the concept of generalized linear models is applicable as described by Fahrmeir and Tutz (2001). Fitting observations to functions of this type requires to rectify the originally measured data with the inverse of the pertinent model function (in our case, $\Phi^{-1}$ ) and to fit the rectified data in the familiar framework of a linear (in our case multilinear) regression model. The ultimate reason for the superiority of the fit in the rectified mode is that the data distribution in this mode is normal while in the nonlinear mode it is not; thus, the maximum likelihood principle necessary for the eventual inference of the parameter vector applies only in the rectified mode.

The differences between $\mathbf{Q}^{\prime}$ and $\mathbf{Q}$ are yet below the significance level (compare fourth column of Table 1 with second column of Table 3). All evaluations reported in the present study have been done with the linear fit. ${ }^{6} \mathbf{Q}$ is then used for the plots of the state function $N(\tau)$ for both seasons (Figs. 8 and 10).

\footnotetext{
${ }^{6}$ Except the evaluations in Table 1 and in Fig. 6-these have still been made with the nonlinear fit.
} 


\section{Appendix 2-List of stations}

Table 6 Austrian and Swiss climate stations used in this study

\begin{tabular}{|c|c|c|c|c|c|c|c|}
\hline Station name & Altitude (m) & Longitude $\left({ }^{\circ}\right)$ & Latitude $\left({ }^{\circ}\right)$ & $r_{\mathrm{DJF}}$ & $N_{\text {DJF }}$ & $r_{\mathrm{JJA}}$ & $N_{\mathrm{JJA}}$ \\
\hline Hohenau & 155 & 16.90 & 48.62 & -0.58 & 43 & NA & 0 \\
\hline Eisenstadt & 159 & 16.55 & 47.85 & -0.47 & 43 & NA & 0 \\
\hline Schwechat & 184 & 16.57 & 48.10 & -0.66 & 41 & NA & 0 \\
\hline Laa an der Thaya & 187 & 16.38 & 48.72 & -0.65 & 43 & NA & 0 \\
\hline Wien-Hohe Warte & 203 & 16.35 & 48.25 & -0.75 & 46 & NA & 0 \\
\hline Krems & 223 & 15.60 & 48.42 & -0.49 & 42 & NA & 0 \\
\hline Mariabrunn & 226 & 16.23 & 48.20 & -0.82 & 31 & NA & 0 \\
\hline Retz & 256 & 15.95 & 48.75 & -0.56 & 37 & NA & 0 \\
\hline Lugano & 273 & 8.97 & 46.00 & -0.12 & 31 & NA & 0 \\
\hline Sankt Pölten & 277 & 15.62 & 48.20 & -0.75 & 42 & NA & 0 \\
\hline Hörsching & 298 & 14.18 & 48.23 & -0.74 & 47 & NA & 0 \\
\hline Rheinfelden & 300 & 7.80 & 47.18 & -0.60 & 35 & NA & 0 \\
\hline Bad Gleichenberg & 303 & 15.90 & 46.87 & -0.67 & 36 & NA & 0 \\
\hline Basel-Binningen & 316 & 7.58 & 47.55 & -0.61 & 39 & NA & 0 \\
\hline Graz Flughafen & 340 & 15.43 & 46.98 & -0.62 & 46 & NA & 0 \\
\hline Reichersberg & 350 & 13.37 & 48.33 & -0.69 & 44 & NA & 0 \\
\hline Graz Universität & 366 & 15.45 & 47.07 & -0.63 & 45 & NA & 0 \\
\hline Gleisdorf & 375 & 15.70 & 47.10 & -0.59 & 48 & NA & 0 \\
\hline Grossraming & 379 & 14.52 & 47.88 & -0.72 & 41 & NA & 0 \\
\hline Locarno-Monti & 379 & 8.78 & 46.17 & -0.19 & 40 & NA & 0 \\
\hline Grono & 382 & 9.15 & 46.25 & -0.51 & 41 & NA & 0 \\
\hline Kremsmünster & 383 & 14.13 & 48.05 & -0.72 & 46 & NA & 0 \\
\hline Lobming & 400 & 15.18 & 47.05 & -0.61 & 47 & NA & 0 \\
\hline Wörtberg & 400 & 16.10 & 47.22 & -0.66 & 45 & NA & 0 \\
\hline Montreux-Clarens & 405 & 6.90 & 46.45 & -0.68 & 35 & NA & 0 \\
\hline Delmont & 415 & 7.35 & 47.37 & -0.67 & 42 & NA & 0 \\
\hline Oberleis & 420 & 16.37 & 48.55 & -0.48 & 35 & NA & 0 \\
\hline Geneve-Cointrin & 420 & 6.12 & 46.25 & -0.65 & 37 & NA & 0 \\
\hline Salzburg Flughafen & 430 & 13.00 & 47.80 & $-\mathbf{0 . 8 0}$ & 47 & NA & 0 \\
\hline Zuerich Flughafen & 431 & 8.53 & 47.48 & -0.62 & 35 & NA & 0 \\
\hline Hallau & 432 & 8.47 & 47.70 & -0.42 & 37 & NA & 0 \\
\hline Biel & 433 & 7.25 & 47.12 & $-\mathbf{0 . 7 3}$ & 44 & NA & 1 \\
\hline Changins sur Nyon & 435 & 6.23 & 46.40 & -0.27 & 14 & NA & 0 \\
\hline Bregenz & 436 & 9.75 & 47.50 & -0.70 & 48 & NA & 0 \\
\hline Schaffhausen-Ch-Fels & 437 & 8.62 & 47.68 & -0.62 & 32 & NA & 0 \\
\hline Guettingen & 438 & 9.28 & 47.60 & -0.37 & 23 & NA & 0 \\
\hline Feldkirch & 440 & 9.60 & 47.27 & -0.74 & 48 & NA & 0 \\
\hline Klagenfurt & 447 & 14.33 & 46.65 & -0.34 & 39 & NA & 0 \\
\hline Altdorf & 451 & 8.63 & 46.87 & -0.68 & 46 & NA & 0 \\
\hline Luzern & 456 & 8.30 & 47.03 & -0.67 & 45 & NA & 0 \\
\hline Bad Ischl & 469 & 13.63 & 47.72 & -0.59 & 39 & NA & 0 \\
\hline Altstaetten & 473 & 9.53 & 47.38 & -0.74 & 45 & NA & 0 \\
\hline Oeschberg & 482 & 7.62 & 47.13 & -0.75 & 40 & NA & 0 \\
\hline Sion-Aerodrom & 483 & 7.33 & 46.22 & -0.42 & 27 & NA & 0 \\
\hline Reichenau & 486 & 15.83 & 47.70 & -0.67 & 49 & NA & 0 \\
\hline Neuchatel & 487 & 6.95 & 47.00 & -0.66 & 41 & NA & 0 \\
\hline Bruck an der Mur & 489 & 15.27 & 47.42 & -0.64 & 49 & NA & 0 \\
\hline Mondsee & 491 & 13.37 & 47.85 & -0.74 & 49 & NA & 0 \\
\hline Kufstein & 492 & 12.17 & 47.57 & -0.54 & 38 & NA & 0 \\
\hline Hieflau & 492 & 14.75 & 47.60 & -0.28 & 38 & NA & 0 \\
\hline Bad Ragaz & 496 & 9.50 & 47.02 & -0.60 & 49 & NA & 0 \\
\hline Sankt Michael Bleiburg & 500 & 12.35 & 46.92 & -0.54 & 26 & NA & 0 \\
\hline Stift Zwettel & 505 & 15.20 & 48.62 & -0.64 & 46 & NA & 0 \\
\hline
\end{tabular}


Table 6 (continued)

\begin{tabular}{|c|c|c|c|c|c|c|c|}
\hline Station name & Altitude (m) & Longitude $\left({ }^{\circ}\right)$ & Latitude $\left(^{\circ}\right)$ & $r_{D J F}$ & $N_{D J F}$ & $r_{J J A}$ & $N_{J J A}$ \\
\hline Glarus & 515 & 9.07 & 47.05 & -0.57 & 36 & NA & 0 \\
\hline Jenbach & 530 & 11.75 & 47.38 & -0.54 & 37 & NA & 0 \\
\hline Taenikon & 536 & 8.90 & 47.48 & -0.70 & 35 & NA & 0 \\
\hline Sion & 542 & 7.37 & 46.23 & -0.24 & 17 & NA & 0 \\
\hline Freistadt & 548 & 14.50 & 48.50 & -0.55 & 47 & NA & 0 \\
\hline Chur-Ems & 555 & 9.53 & 46.87 & -0.45 & 48 & NA & 0 \\
\hline Bern-Liebefeld & 570 & 7.42 & 46.93 & -0.48 & 44 & NA & 0 \\
\hline Interlaken & 574 & 7.87 & 46.68 & -0.59 & 35 & NA & 1 \\
\hline Comprovasco & 575 & 8.93 & 46.87 & -0.44 & 32 & NA & 0 \\
\hline Innsbruck Universität & 577 & 11.38 & 47.25 & $-\mathbf{0 . 5 3}$ & 49 & NA & 0 \\
\hline Innsbruck Flugplatz & 579 & 11.35 & 47.25 & -0.54 & 49 & NA & 0 \\
\hline Pabneukirchen & 595 & 14.82 & 48.32 & -0.66 & 45 & NA & 0 \\
\hline Meiringen & 595 & 8.18 & 46.73 & -0.47 & 47 & NA & 1 \\
\hline Kolbnitz & 603 & 13.30 & 46.87 & -0.42 & 31 & NA & 0 \\
\hline Ebnat-Kappel & 623 & 9.12 & 47.28 & -0.72 & 42 & NA & 0 \\
\hline Fribourg & 634 & 7.12 & 46.77 & -0.57 & 41 & NA & 0 \\
\hline Mayrhofen & 643 & 11.85 & 47.15 & $-\mathbf{0 . 5 3}$ & 41 & NA & 0 \\
\hline Reisach & 646 & 13.15 & 46.63 & -0.44 & 25 & NA & 0 \\
\hline Schiers & 651 & 9.68 & 46.98 & -0.15 & 19 & NA & 0 \\
\hline Lienz & 668 & 12.78 & 46.82 & -0.57 & 33 & NA & 0 \\
\hline Zeltweg & 669 & 14.78 & 47.20 & $-\mathbf{0 . 3 2}$ & 41 & NA & 0 \\
\hline Bad Aussee & 675 & 13.78 & 47.62 & -0.24 & 35 & NA & 0 \\
\hline Mürzzuschlag & 700 & 15.68 & 47.60 & -0.34 & 43 & NA & 0 \\
\hline Irdning & 702 & 14.10 & 47.50 & -0.20 & 43 & NA & 0 \\
\hline Haidenhaus & 702 & 9.02 & 47.65 & -0.82 & 38 & NA & 0 \\
\hline Kollerschlag & 725 & 13.83 & 48.60 & -0.54 & 46 & NA & 1 \\
\hline Fey & 737 & 7.27 & 46.18 & 0.21 & 17 & NA & 0 \\
\hline Zell am See & 755 & 12.78 & 47.30 & -0.02 & 39 & NA & 0 \\
\hline Langau im Emmental & 755 & 7.80 & 46.93 & -0.58 & 48 & NA & 1 \\
\hline St. Gallen & 779 & 9.40 & 47.43 & $-\mathbf{0 . 8 0}$ & 50 & NA & 1 \\
\hline Stein Appenzell Ausserrhoden & 780 & 9.35 & 47.38 & -0.78 & 31 & NA & 0 \\
\hline Heiden & 800 & 9.53 & 47.43 & -0.71 & 36 & NA & 1 \\
\hline Landeck & 818 & 10.57 & 47.13 & $-\mathbf{0 . 3 8}$ & 47 & NA & 0 \\
\hline Schoppernau & 835 & 10.02 & 47.30 & -0.02 & 22 & NA & 6 \\
\hline Seckau & 855 & 14.77 & 47.27 & -0.37 & 34 & NA & 1 \\
\hline Reutte & 870 & 10.75 & 47.50 & -0.54 & 34 & NA & 1 \\
\hline Mariazell/Sankt Sebastian & 875 & 15.30 & 47.78 & -0.27 & 41 & NA & 0 \\
\hline Einsiedeln & 910 & 8.75 & 47.13 & -0.42 & 42 & NA & 1 \\
\hline Rauris & 945 & 13.00 & 47.22 & -0.05 & 34 & 0.54 & 3 \\
\hline Vaettis & 957 & 9.43 & 46.92 & -0.13 & 25 & NA & 0 \\
\hline Elm & 965 & 9.18 & 46.93 & -0.41 & 32 & NA & 3 \\
\hline Chateau d'Oex & 985 & 7.15 & 46.48 & -0.11 & 42 & NA & 1 \\
\hline Tamsweg & 1,012 & 13.80 & 47.12 & -0.15 & 40 & NA & 1 \\
\hline Engelberg & 1,035 & 8.42 & 46.82 & -0.27 & 27 & -0.94 & 3 \\
\hline La Brevine & 1,042 & 6.60 & 46.98 & -0.29 & 25 & NA & 1 \\
\hline Preitenegg & 1,055 & 14.92 & 46.93 & -0.32 & 37 & NA & 0 \\
\hline Guttanen & 1,055 & 8.30 & 46.65 & -0.14 & 33 & NA & 6 \\
\hline Chaumont & 1,073 & 6.98 & 47.05 & -0.46 & 40 & NA & 0 \\
\hline Robbia/Poschiavo & 1,078 & 10.07 & 46.35 & -0.24 & 45 & NA & 0 \\
\hline Oberiberg & 1,087 & 8.78 & 47.03 & -0.08 & 14 & 0.83 & 3 \\
\hline Loibl & 1,098 & 14.25 & 46.45 & -0.49 & 28 & NA & 3 \\
\hline Holzgau & 1,100 & 10.35 & 47.25 & -0.14 & 23 & NA & 4 \\
\hline Bad Gastein & 1,100 & 13.13 & 47.12 & 0.04 & 28 & 0.93 & 4 \\
\hline Disentis & 1,190 & 8.85 & 46.70 & -0.08 & 35 & -0.18 & 7 \\
\hline Schröcken & 1,263 & 10.08 & 47.25 & -0.28 & 13 & 0.22 & 20 \\
\hline Scuol (Schuls) & 1,295 & 10.28 & 46.80 & -0.21 & 25 & NA & 5 \\
\hline
\end{tabular}


Table 6 (continued)

\begin{tabular}{|c|c|c|c|c|c|c|c|}
\hline Station name & Altitude (m) & Longitude $\left({ }^{\circ}\right)$ & Latitude $\left({ }^{\circ}\right)$ & $r_{\mathrm{DJF}}$ & $N_{\text {DJF }}$ & $r_{\mathrm{JJA}}$ & $N_{\mathrm{JJA}}$ \\
\hline Stolzalpe & 1,305 & 14.20 & 47.12 & -0.23 & 32 & NA & 0 \\
\hline Adelboden & 1,320 & 7.57 & 46.50 & -0.36 & 30 & 0.12 & 9 \\
\hline Reckingen & 1,325 & 8.25 & 46.47 & 0.71 & 6 & -0.06 & 5 \\
\hline Sankt Jakob im Defreggental & 1,400 & 12.35 & 46.92 & -0.27 & 15 & NA & 6 \\
\hline Schöckl & 1,436 & 15.47 & 47.20 & -0.43 & 20 & NA & 2 \\
\hline Andermatt & 1,442 & 8.60 & 46.63 & -0.03 & 7 & -0.15 & 16 \\
\hline Montana & 1,495 & 7.48 & 46.32 & 0.04 & 27 & NA & 4 \\
\hline Simplon Dorf & 1,495 & 8.05 & 46.20 & -0.17 & 26 & 0.68 & 3 \\
\hline Bosco-Gurin & 1,505 & 8.50 & 46.32 & -0.23 & 11 & -0.91 & 3 \\
\hline Kanzelhöhe & 1,526 & 13.90 & 46.67 & -0.28 & 20 & -0.18 & 6 \\
\hline Graechen & 1,550 & 7.83 & 46.20 & -0.23 & 23 & -0.06 & 4 \\
\hline Galtür & 1,583 & 10.18 & 46.97 & 0.27 & 11 & $-\mathbf{0 . 3 3}$ & 23 \\
\hline Davos & 1,590 & 9.87 & 46.82 & 0.08 & 9 & -0.13 & 27 \\
\hline Hinterrhein & 1,611 & 9.18 & 46.52 & -0.38 & 8 & -0.08 & 14 \\
\hline Feuerkogel & 1,618 & 13.73 & 47.82 & -0.25 & 13 & -0.32 & 23 \\
\hline Zermatt & 1,638 & 7.75 & 46.03 & -0.21 & 15 & NA & 3 \\
\hline Muerren & 1,639 & 7.88 & 46.57 & -0.24 & 15 & 0.11 & 23 \\
\hline San Bernardino Dorf & 1,639 & 9.18 & 46.47 & -0.27 & 13 & NA & 2 \\
\hline La Dole & 1,670 & 6.10 & 46.43 & -0.41 & 12 & -0.04 & 7 \\
\hline Saas Almagell & 1,673 & 7.95 & 46.10 & -0.54 & 9 & -0.27 & 6 \\
\hline Sils Maria & 1,802 & 9.77 & 46.43 & -0.36 & 6 & -0.23 & 17 \\
\hline Arosa & 1,840 & 9.68 & 46.78 & 0.04 & 5 & -0.41 & 42 \\
\hline Obergurgel & 1,938 & 11.02 & 46.87 & 0.29 & 4 & -0.46 & 40 \\
\hline Buffalora & 1,970 & 10.27 & 46.40 & 0.86 & 3 & -0.35 & 22 \\
\hline Grimsel Hospiz & 1,980 & 8.33 & 46.57 & NA & 2 & -0.49 & 46 \\
\hline Mooserboden & 2,036 & 12.72 & 47.15 & -0.15 & 3 & -0.29 & 42 \\
\hline Krippenstein & 2,050 & 13.70 & 47.52 & -0.00 & 3 & -0.40 & 46 \\
\hline Villacher Alpe & 2,140 & 13.67 & 46.60 & $-\mathbf{0 . 3 3}$ & 12 & -0.60 & 43 \\
\hline Patscherkofel & 2,247 & 11.45 & 47.20 & 0.36 & 13 & -0.42 & 45 \\
\hline Ospizio Bernina & 2,256 & 10.02 & 46.42 & -0.62 & 3 & -0.38 & 27 \\
\hline Guetsch ob Andermatt & 2,280 & 8.62 & 46.65 & NA & 1 & -0.57 & 32 \\
\hline Grand St. Bernhard & 2,479 & 7.17 & 45.87 & NA & 0 & NA & 0 \\
\hline Saentis & 2,490 & 9.35 & 47.25 & NA & 2 & -0.20 & 48 \\
\hline Weissfluhjoch & 2,690 & 9.80 & 46.83 & NA & 2 & $-\mathbf{0 . 7 3}$ & 48 \\
\hline Sonnblick & 3,105 & 12.95 & 47.05 & NA & 0 & -0.99 & 4 \\
\hline Jungfraujoch & 3,580 & 7.98 & 46.55 & NA & 0 & NA & 0 \\
\hline
\end{tabular}

Stations are ordered according to altitude. Color key: red (blue), stations that are excluded because they do not pass the weak (strong) correlation criterion (see also Fig. 3); black, stations entering the eventual data fit

$r$ correlation coefficient between snow duration and European temperature, $N$ number of processed station seasons, $N A$ no processed data with nonzero variance available for this station in this season

\section{References}

Barry RG (1992) Mountain weather and climate. Routledge, London

Beniston M (1997) Variations of snow depth and duration in the Swiss Alps over the last 50 years: links to changes in largescale climatic forcings. Clim Change 36:281-300

Beniston M (2010) Impacts of climatic change on water and associated economic activities in the Swiss Alps. J Hydrol 412 413:291-296

Bloeschl G, Sivapalan M (1995) Scale issues in hydrological modelling: a review. Hydrol Process 9:251-290

Brohan P, Kennedy JJ, Harris I, Tett SFB, Jones PD (2006) Uncertainty estimates in regional and global observed temperature changes: a new dataset from 1850. J Geophys Res 111:D12106
Bronstein IN, Semendjajew KA, Musiol G, Mühlig H (1999) Taschenbuch der Mathematik. Verlag Harri Deutsch

Clow DW (2010) Changes in the timing of snowmelt and streamflow in Colorado: a response to recent warming. J Clim 23:2293-2306

Dery SJ, Stieglitz M, McKenna EC, Wood EF (2005) Characteristics and trends of river discharge into Hudson, James, and Ungava Bays 1964-2000. J Clim 18:2540-57

Durand Y, Giraud G, Laternser M, Etchevers P, Merindol L, Lesaffre B (2009) Reanalysis of 47 years of climate in the French Alps (1958-2005): climatology and trends for snow cover. J Appl Meteorol Climatol 48:2487-2512

Efron B, Tibshirani RJ (1998) An introduction to the bootstrap. Chapman \& Hall/CRC

Fahrmeir L, Tutz G (2001) Multivariate statistical modelling based on generalized linear models. 2nd edn. Springer Verlag New York, Berlin, Heidelberg 
Fliri F (1992) Der Schnee in Nord- und Osttirol 1895-1991Ein Graphik-Atlas, Band 1+2. Universitätsverlag Wagner, Innsbruck

Gottfried M, Hantel M, Maurer C, Toechterle R, Pauli H, Grabherr G (2011) Coincidence of the alpine-nival ecotone with the summer snowline. Environ Res Lett 6:12 pp. link: http:// iopscienceioporg/1748-9326/6/1/014013/

Haiden T, Hantel M (1992) Klimamodelle: Mögliche Aussagen für Österreich, Österreichische Akademie der Wissenschaften, Wien, pp 2.1-2.14

Hann J (1883) Handbuch der Klimatologie. Verlag von J. Engelhorn, Stuttgart

Hann J (1908) Handbuch der Klimatologie. Band I Allgemeine Klimalehre. Bibliothek Geographischer Handbücher, N.F. Verlag von J. Engelhorn, Stuttgart

Hantel M (1992) The climate of seasonal snow cover duration in the Alps. Austrian Contributions to the IGBP-National Committee for the IGBP-Austrian Academy of Sciences I:13-15

Hantel M (2005) Observed global climate. Landolt-Börnstein, New Series, Volume V/6, Springer, Berlin

Hantel M, Hirtl-Wielke LM (2007) Sensitivity of Alpine snow cover to European temperature (paper III). Int J Climatol 27:1265-1275

Hantel M, Maurer C (2011) The median winter snowline in the Alps. Meteorol Z 20(3):267-276

Hantel M, Ehrendorfer M, Haslinger A (2000) Climate sensitivity of snow cover duration in Austria (paper I). Int J Climatol 20:615-640

Hermes K (1955) Die Lage der oberen Waldgrenze in den Gebirgen der Erde und ihr Abstand zur Schneegrenze. Kölner geogr. Arb. 5, Geogr. Inst., Univ. Köln

Hosmer DW, Lemeshow S (2000) Applied logistic regression. Wiley, New York

Karl TR, Trenberth KE (2003) Modern Global climate change. Science 302:1719-1723

Kaur R, Kulkarni AV, Chaudhary BS (2010) Using RESOURCESAT-1 data for determination of snow cover and snowline altitude, Baspa Basin, India. Ann Glaciol 51: 9-13
Körner C (2003) Alpine plant life-functional plant ecology of high mountain ecosystems. 2nd edn. Springer, Berlin

Laternser M, Schneebeli M (2003) Long-term snow climate trends of the Swiss Alps (1931-99). Int J Climatol 23:733750

Lemke P, Ren J, Alley RB, Allison I, Carrasco J, Flato G, Fujii Y, Kaser G, Mote P, Thomas RH, Zhang T (2007) Observations: changes in snow, ice and frozen ground. Cambridge University Press, Cambridge

Louis H (1955) Schneegrenze und Schneegrenzbestimmung. Geographisches Taschenbuch 1954/55. Wiesbaden

Mazumdar J (1999) An introduction to mathematical physiology and biology. Cambridge University Press, Cambridge

Nagy L, Grabherr G (2009) The Biology of Alpine habitats. Oxford University Press, Oxford

NOAA/NESDIS/OSDPD/SSD (2004) IMS daily Northern hemisphere snow and ice analysis at $4 \mathrm{~km}$ and $24 \mathrm{~km}$ resolution. National Snow and Ice Data Center, Digital media, Boulder, $\mathrm{CO}$

Parajka J, Pepe M, Rampini A, Rossi S, Blöschl G (2010) A regional snow-line method for estimating snow cover from modis during cloud cover. J Hydrol 381:203-212

Parker SP (1997) Dictionary of earth science. McGraw-Hill, New York

Reuter H, Hantel M, Steinacker R (2001) Meteorologie. Walter de Gruyter, Berlin, pp 131-310

Scherrer SC, Appenzeller C, Laternser M (2004) Trends in Swiss alpine snow days: the role of local- and large-scale climate variability. Geophys Res Lett 31:L13215

Steinacker R (1983) Diagnose und Prognose der Schneefallgrenze. Wetter und Leben 35:81-90

Wielke LM, Haimberger L, Hantel M (2004) Snow cover duration in Switzerland compared to Austria (paper II). Meteorol Z 13:13-17

Wielke LM, Haimberger L, Hantel M (2005) Corrigendum to 'snow cover duration in Switzerland compared to Austria'(paper II). Meteorol Z 14:857

Wipf S, Stoeckli V, Bebi P (2009) Winter climate change in alpine tundra: plant responses to changes in snow depth and snowmelt timing. Clim Change 94:105-121 